\title{
Large-Scale Mapping of Boreal Forest in SIBERIA using ERS Tandem Coherence and JERS Backscatter Data
}

Wolfgang Wagner ${ }^{1}$, Adrian Luckman ${ }^{2}$, Jan Vietmeier ${ }^{1}$, Kevin Tansey ${ }^{2}$, Heiko Balzter ${ }^{3}$, Christiane Schmullius ${ }^{4}$, Malcolm Davidson ${ }^{5}$, David Gaveau ${ }^{3}$, Michael Gluck ${ }^{6}$, Thuy Le Toan $^{5}$, Shaun Quegan ${ }^{7}$, Anatoly Shvidenko ${ }^{6}$, Andreas Wiesmann ${ }^{8}$, Jiong Jiong $\mathrm{Yu}^{7}$

${ }^{1}$ German Remote Sensing Data Center, German Aerospace Center, Wessling, Germany

${ }^{2}$ Department of Geography, University of Wales, Swansea, U.K

${ }^{3}$ Centre for Ecology and Hydrology, Monks Wood, Abbots Ripton, U.K

${ }^{4}$ Institute of Geography of the Friedrich-Schiller-University, Jena, Germany

${ }^{5}$ Centre d'Etudes Spatiales de la Biosphere, Toulouse, France

${ }^{6}$ Institute for Applied System Analysis, Laxenburg, Austria

${ }^{7}$ Sheffield Centre for Earth Observation Science, University of Sheffield, Sheffield, U.K

${ }^{8}$ Gamma Remote Sensing, Bern, Switzerland

Wolfgang Wagner is now with the Institute of Photogrammetry and Remote Sensing, Vienna University of Technology, Austria, Kevin Tansey with the Institute for Environment and Sustainability of the Joint Research Centre of the European Commission, Ispra, Italy, David Gaveau with the Wildlife Conservation Society-Indonesia Program, Bogor, Indonesia, Malcolm Davidson with the European Space Agency, Noordwijk, The Netherlands, Michael Gluck with the Ontario Ministry of Natural Resources, Thunder Bay, Canada, Jiong Jiong Yu with Surface Inspection Limited, Bristol, United Kingdom, and Jan Vietmeier is GIS consultant in Köln, Germany.

Address for correspondence: Prof. Wolfgang Wagner, Institute of Photogrammetry and Remote Sensing, Vienna University of Technology, Gusshausstr. 27-29, 1040 Vienna, Austria Tel: +43-1-58801-122-25, Fax: +43-1-58801-122-99, E-mail: ww@ipf.tuwien.ac.at 


\section{Abstract}

2 Siberia's boreal forests represent an economically and ecologically precious resource, a 3 significant part of which is not monitored on a regular basis. Synthetic Aperture Radars 4 (SARs), with their sensitivity to forest biomass, offer mapping capabilities that could provide 5 valuable up-to-date information, for example about fire damage or logging activity. The 6 European Commission SIBERIA project had the aim of mapping an area of approximately 1 7 million $\mathrm{km}^{2}$ in Siberia using SAR data from two satellite sources: the tandem mission of the 8 European Remote Sensing Satellites ERS-1/2 and the Japanese Earth Resource Satellite 9 JERS-1. Mosaics of ERS tandem interferometric coherence and JERS backscattering coefficient show the wealth of information contained in these data but they also show large

11 differences in radar response between neighbouring images. To create one homogeneous 12 forest map, adaptive methods which are able to account for brightness changes due to environmental effects were required. In this paper an adaptive empirical model to determine growing stock volume classes using the ERS tandem coherence and the JERS backscatter data is described. For growing stock volume classes up to $80 \mathrm{~m}^{3} / \mathrm{ha}$, accuracies of over $80 \%$ are achieved for over a hundred ERS frames at a spatial resolution of $50 \mathrm{~m}$. 


\section{Introduction}

Siberian forests contain roughly half the world's growing stock volume of coniferous species, making them an economically and ecologically precious resource (Nilsson and Shvidenko, 1998). Given the vastness and remoteness of the area, high-resolution satellite imagery is indispensable for mapping and monitoring these forests. To collect Synthetic Aperture Radar (SAR) images the German Remote Sensing Data Center (DLR-DFD) deployed a mobile receiving station in Ulaanbaatar, Mongolia, in 1997 (Schmullius and Rosenqvist, 1997). SAR data from the European Remote Sensing Satellites ERS-1 and ERS-2 (C-band) and the Japanese Earth Resource Satellite JERS-1 (L-band) were acquired during two campaigns in fall 1997 and summer 1998. For the first time, this effort provided a near complete coverage of central Siberia with ERS tandem pairs and JERS images providing an excellent opportunity to map forest attributes in this region.

The potential of SAR for forestry applications has been highlighted in many studies (Leckie and Ranson, 1998). Traditionally, most of these studies have been confined to relatively small areas where on-ground data are available to study the behavior of the SAR data in detail. In this way, rich insights into the local relationships between SAR data and forest parameters can be gained, often also as a function of time and environmental conditions. Naturally, scientists strive to obtain the best possible results by optimizing their classification methodology. Consequently, algorithms developed over small study areas tend to be sitespecific and can in many cases not be transferred successfully to other areas. On the other side of the spectrum are large-scale mapping projects which have been initiated in recent years driven by the need to better understand the functioning and dynamics of whole forest ecosystems, from individual tree species to forest communities. International efforts like the Global Rain Forest Mapping (GRFM) project brought forth an entirely new way of performing remote sensing of the Earth by combining large-area coverage with high spatial 
resolution (Rosenqvist et al., 2000). GRFM achieved the collection of JERS-1 SAR data over the entire tropical belt and produced mosaics at a spatial resolution of $100 \mathrm{~m}$. These mosaics have subsequently been used to derive thematic information over very large areas (De Grandi et al., 2002).

An "intermediate" approach was pursued by the European Commission-funded SIBERIA project which was set up to map the forests over an area of approximately 1 million $\mathrm{km}^{2}$ in central Siberia $\left(51-60^{\circ} \mathrm{N}, 85-110^{\circ} \mathrm{E}\right)$ based on the data collected at Ulaanbaatar. The project combined detailed analysis over selected study areas with efforts to produce a large-area, high-resolution forest map. This required a different view on the analysis of the ground data: the emphasis was now on the identification of common behavior over all test sites rather than model optimization over individual test sites.

To represent the specific zonal regularity of forests and vegetation within the entire study region, an extensive forest data base was assembled in a joint effort of the International Institute for Applied System Analysis (IIASA) and several Russian partners. Forest inventory data from 50 test areas, covering a total area of 1,959,340 ha, was compiled and used to a varying extent in the exploratory analysis, model development and accuracy assessment.

To produce the forest map, the SIBERIA project followed an alternative approach to the one adapted by the GRFM project, which used image mosaics as input into data-based classifiers. A point to consider is that radiometric information is partially lost in image mosaics after matching to suppress striping and environmental effects. Matching results in internally consistent mosaics that can be used as input into classification algorithms that rely on relative comparisons of local image amplitude statistics and texture measures (De Grandi et al., 2000). However, it impacts the physical interpretation of the data in relation to geophysical parameters and environmental effects. This problem is avoided by firstly classifying the calibrated images and only then mosaicing the classified images. Since the SIBERIA team 
decided to follow this approach, the challenge was to develop an adaptive classifier which yields comparable results over all image frames in the entire area.

The paper is structured as follows: after a discussion of the information content of the SAR data base (Section 2), the project area and the various data sources are described (Section 3). Then the processing steps to obtain geocoded, calibrated images are discussed (Section 4). The exploratory analysis of the database focuses on the dependence of the ERS interferometric coherence and the JERS backscattering coefficient on the growing stock volume of forests and environmental conditions (Section 5). Finally, the adaptive empirical model used to produce the forest map is introduced and the main results of the validation effort are reported (Section 6). A detailed error analysis of the SIBERIA forest map can be found in a separate paper (Balzter et al., in press).

\section{ERS and JERS SAR in Forestry Applications}

The three main radar parameters which can be derived from the ERS tandem and JERS acquisitions are the backscattering coefficients at C- and L-band and the ERS tandem coherence (one-day repeat pass). Backscatter from forest canopies is a complex phenomenon as it depends on the size, shape, and dielectric properties of the scattering elements in the vegetation canopy and the surface properties (Ulaby et al., 1990). For the ERS SAR (C-band, $23^{\circ}$ incidence angle, VV polarization) backscatter from a forest canopy arises primarily by leaves, needles, twigs and small branches which are characterized by their high number density (Le Toan et al., 2002). For young forest stands with low levels of biomass, a contribution from the forest ground is also received. With increasing biomass, the number of scattering elements becomes sufficiently large to completely mask the scattering from the ground and the signal reaches a level of saturation. Depending on the canopy and ground conditions (soil moisture content, freeze/thaw, roughness etc.) the C-band backscattering coefficient may decrease or increase until saturation is reached (Pulliainen et al., 1996). For 
biomass levels larger than the saturation point, backscatter is very stable over time, a characteristic which has been exploited for mapping of forest extent (Quegan at al., 2000a). As guiding value, the saturation point at C-band is often reported to be around $20-30 \mathrm{t} / \mathrm{ha}$ above-ground dry biomass, which corresponds to about $50 \mathrm{~m}^{3} /$ ha growing stock volume (Imhoff, 1995, Le Toan et al., 2002).

For the longer wavelength of JERS SAR (L-band, $35^{\circ}$ incidence angle, HH polarization), canopy scattering and attenuation is mainly determined by the size and orientation of the branches. While ground conditions also affect backscatter for low biomass levels, the majority of studies have observed that JERS backscatter increases, with few exceptions, with increasing biomass over tropical (Luckman et al., 1998; Santos et al., 2002, Castel et al., 2002; Kuplich et al., 2000) and boreal forests (Pulliainen et al., 1999, Fransson and Israelsson, 1999). However, the backscatter level and sensitivity vary with tree species, non-forest vegetation and environmental conditions. Saturation is normally observed at around 40-50 t/ha or $80 \mathrm{~m}^{3} /$ ha of biomass and growing stock volume respectively (Imhoff, 1995, Le Toan et al., 2002).

In addition to the backscatter intensity, the phase stability, or interferometric coherence, between image pairs, has proven to be a valuable source of information in forestry (Balzter, 2001). The coherence is a measure of the correlation between two complex SAR images taken from slightly different orbital positions. The coherence will be high (near 1) if the recorded radar echoes represent nearly the same interaction with the observed target between the two images (Zebker and Villasenor, 1992).

The two main effects that cause the coherence to decrease are normally referred to as temporal and volume decorrelation. Temporal decorrelation arises when the backscattering characteristics of the target change between the acquisitions as a result of changing moisture conditions or other environmental effects. Over forested terrain, temporal decorrelation due to 
118 wind-induced movement of scatterers (needles, branches) near the tree-tops between one acquisition to the next, may be significant (Sarabandi and Wilsen, 2000). Since temporal decorrelation is normally quite strong, it is advantageous to choose a short repeat-pass interval, and thus the ERS-1/2 tandem data have become the preferred data source for forest applications. Volume decorrelation arises when the scattering elements of the Earth's surface are not confined to a narrow surface layer but are distributed within a volume, giving rise to single and multiple scattering, such as is the case for forests (Askne et al., 1997). Gaveau (2002) shows that the distance between neighboring trees and the vertical structure of the boreal forest canopy have an impact on volume decorrelation. For the case of ERS-1/2 tandem data (small baseline), temporal decorrelation is normally stronger than volume decorrelation (Askne and Smith, 1996).

129 Early results obtained using ERS repeat-pass data by Wegmüller and Werner (1995) and Hagberg et al. (1995) showed that the interferometric coherence is significantly lower over forest than over open canopies, short vegetation, bare soils and urban areas. Subsequent studies of ERS-1/2 tandem data demonstrated in particular that the one-day repeat pass coherence is useful in land use mapping (Strozzi et al., 2000) and estimation of stem volume in forests (Smith et al., 1998; Koskinen et al., 2001; Santoro et al., 2002). Hyyppä et al. (2000) found that, compared to the JERS and ERS intensity images, the ERS tandem coherence was best suited to predicting height, basal area and stem volume over a 600 ha boreal forest site in southern Finland. This paper showed, however, that airborne measurements (profiling radar, aerial photographs, imaging spectrometer) and even optical satellite images (SPOT and Landsat) included more information than the ERS interferometric data for their test area. The transferability of the methods was not tested in this study. 


\section{Study Area and Forest inventory Database}

142

143

144

\subsection{Geographic Area}

The study area is situated between the Yenisey River in the west and the Baikal Lake basin in the east and covers territories of four administrative regions of Russia (Krasnoyarsk Kray and Irkutsk Oblast; relatively small parts of Republics Buryatia and Touva). Diverse landforms plains, plateaus, mountains - are represented in the region. A mountainous area stretches along the southern boundary of the region, represented by Kuznezky Ala-Tau, Zapadny Sayan, and Vostochny Sayan. A major part of the territory lies in a typical boreal forest zone and is comprised of middle and southern taiga sub-zones. The percentage of forest cover is high even for the taiga zone, and as a rule reaches $60-70 \%$. To the south from Krasnoyarsk (about $57^{\circ} \mathrm{N}$ ), deciduous forests are common, mixed with islands of forest steppe and steppe. While landscape diversity is very high, ecosystem and species diversity is low: there are approximately 25 tree and 80 shrub indigenous species in the forests of the region. Major tree species of non-mountain forests are larch (Larix dahurica and L. sibirica) and pine (Pinus sylvestris), covering approximately $2 / 3$ of the forested areas. Larch usually dominates in northern regions, but is present in all forest formations. Spruce (Picea sibirica) grows in river valleys and on watersheds above $400-500 \mathrm{~m}$ above sea level. Cedar (Pinus sibirica) is typical of "mist" forests and occupies high plateaus. Secondary deciduous forests (mostly dominated by birch) cover significant areas, but do not generate an explicitly delineated zone.

Forest productivity increases from north to south. Growing stock volume of mature forests is around $150 \mathrm{~m}^{3} /$ ha in the middle taiga and $230-250 \mathrm{~m}^{3} / \mathrm{ha}$ in the southern taiga. A major part of the forests is represented by mature forests (more than $60 \%$ for large regions). The main types of disturbances include fires, insect outbreaks and harvesting. The most disturbed forests are found along the Trans-Siberian railway and around cities and industrial centres (e.g. Krasnoyarsk, Irkutsk, Bratsk). Regeneration of forests after disturbances (especially after 
clear cut harvests) is usually accompanied by a change of species, which explains the large areas of birch and aspen forest.

An appropriate coordinate system for presenting the SIBERIA project area is the UTM scheme with an ellipsoid defined by WGS84. The entire study area spans over five UTM East-West zones. For representing a map of the entire area the central zone 47 was chosen. UTM47 coordinates for the project area are:

$$
\text { Top left (m): } \quad \text { Easting: }-200,000 \quad \text { Northing: 6,900,000 }
$$

Bottom right (m): Easting: 1,300,000 Northing: 5,600,000

\subsection{Forest Inventory Data}

The forest data used in this study stem from the Russian forest inventory and are polygonbased. For each polygon, detailed information is available: land cover category, area, short description of land cover, description of elevation and slopes, and detailed information for forests including species composition, age, average diameter and height, relative stocking, growing stock volume, etc.. The sheer size of the SIBERIA project area requires that a large number of test-sites be investigated to represent the full diversity of land cover and topography. The test areas are organized into 13 test territories (Fig. 1), representing major vegetation zones, landforms and levels of land transformation. As a rule, individual forest enterprises were used as test territories. Inside each test territory, up to five test areas were selected. In total, 50 test areas with a surface area between 2,100 and 362,019 ha were collected (Table 1). Each test area is divided into primary land cover units (between 99 and 14,727 polygons) with an average size of about 36 ha. Based on available forest inventory data and initial forest maps (scale 1:50,000), the corresponding database was developed. For the comparison with the SAR data, the field data were converted to raster images and 
manually co-registered to ERS images where there was sufficient overlap. Then the field polygons were shrunk by a two-pixel buffer to compensate for co-registration errors.

$$
<\text { Insert Fig. } 1 \text { about here >> }
$$$$
<\text { Insert Table } 1 \text { about here >> }
$$

The inventories over the test areas were carried out in the years 1995 to 1998; in the majority of the cases in 1997 when also the first Ulaanbaatar acquisition campaign took place (Table 1). Therefore, given the small growth rates of boreal forests (normally $1.5-3 \mathrm{~m}^{3} /$ ha per year; for relatively small areas of young highly productive stands up to $5-73 \mathrm{~m}^{3} / \mathrm{ha}$ ) the errors introduced by the time lag between inventory and SAR acquisition is smaller than the uncertainty inherent in the forest inventory data ( $\pm 15 \%$ according to Russian forest inventory manual). The exception are forest stands which were burnt or logged in the time period between the inventory and the SAR acquisition.

\subsection{SAR Data}

ERS-1 and ERS-2 images were acquired in September and October 1997 giving both autumnal C-band backscatter and tandem coherence. The receiving station was kept in place for a further campaign the following summer. It also acquired a few JERS (L-band) satellite tracks during autumn 1997 and a full coverage of the region during summer 1998 (May to August).

One hundred and twenty-two ERS SAR tandem pairs were processed using the interferometry software of the German Remote Sensing Data Center, Wessling, Germany (Roth et al., 1998). With few exceptions, tandem pair data acquired during fall 1997 were used. Fig. 2 shows the coherence mosaic of the entire SIBERIA area and Fig. 3a the relative coverage with fall 1997 and summer 1998 tandem data.

\footnotetext{
$<$ Insert Fig. 2 around here $>>$
} 
214 Where coherence allowed, DEMs were constructed from the tandem acquisitions and used to 215 improve both the radiometric and geometric properties of the ERS data (Teillet et al., 1985).

216 Such ERS data are labeled as GTC frames (geocoded terrain-corrected) and geographic 217 referencing was achieved with the help of 1:200,000 Russian maps. Where DEMs could not 218 be produced, the GTOPO30, 30 arc-second (resolution of approximately 1km) DEM (U.S.

219 Geological Survey, 1997) was used to optimize geometric accuracy. These data are labeled as GEC frames (geocoded ellipsoid corrected) and geographic referencing was achieved through the use of precision orbital data supplied by ESA. Since the coherence is generally low over forested terrain, DEMs could only be generated for 48 of the 122 ERS frames (Fig. 3b).

JERS SAR data from summer 1998 were processed at the National Space Agency of Japan (NASDA), Tokyo, Japan and at Gamma Remote Sensing, Bern, Switzerland (Wiesmann et al., 1999). The images were geocoded using the GTOPO30 DEM and geographically referenced from orbital data supplied by NASDA.

\section{Preprocessing}

\subsection{ERS-1/2 Co-registration and Geometric Correction}

ERS-1 and ERS-2 tracks generally coincide to within a few hundred meters. Therefore coregistration of these datasets, both from the tandem acquisitions and from the spring acquisition, is a simple procedure involving automatic control point generation through crosscorrelation of image patches and was achieved with sub-pixel accuracy. All ERS data was acquired, calibrated according to standard procedure (Laur et al, 1998), and co-registered on a ESA standard frame basis as single-look-complex (SLC) scenes (i.e. $100 \mathrm{~km}$ x $100 \mathrm{~km}$ images with a small amount of overlap between consecutive frames). After interferometric

236 processing, the data were then re-projected to the UTM reference scheme using the 
interferometric DEM where it was available (GTC frames) and the GTOPO30 DEM where the coherence between tandem pairs was not sufficient for high-resolution DEM production

(GEC frames). Interferometric coherence was calculated from the SLC data using a $4 \times 20$ pixel window (in range and azimuth, respectively). For comparison, a window size of $5 \times 20$ pixels has been used in other forest studies (Hyyppä et al., 2000; Santoro et al., 2002). The pixel-size chosen for the geocoded data was $50 \mathrm{~m}$ (around 40 independent looks).

\subsection{JERS Geometric Correction and Co-registration to ERS Data}

ERS and JERS satellite tracks do not coincide because of differing orbits and swath-widths. Hence a method of registering these two datasets was necessary to produce the multifrequency composite. Since all other data was already co-registered to the ERS frame system, it was decided also to co-register the JERS data to the same ERS frames on a frame-by-frame basis. The JERS data was processed and calibrated according to standard procedure (Shimada, 1996) on a track-by-track basis, rather than as standard frames. Since each track is narrower in width than the standard ERS frame ( 75 km compared to $\sim 100 \mathrm{~km})$ most ERS frames coincided with sections of two JERS tracks and a few needed three neighbouring tracks to give full frame overlap. The JERS tracks were projected into the UTM reference scheme using the GTOPO30 DEM with a pixel size of $50 \mathrm{~m}$.

Co-registration of the re-projected JERS imagery to the geocoded ERS data was achieved by automatically finding ground control points through cross-correlation of image patches followed by a low-order polynomial transformation. Despite the different geometries of ERS and JERS, and the different radar wavelengths used, this automatic method worked satisfactorily in all but a small minority of cases thereby greatly reducing the amount of user input to the procedure and odeled te the geometric accuracy of the match. 


\subsection{JERS Radiometric Matching}

The look-angle of JERS varies by a few degrees across its swath and the effect on scattering processes, particularly in forested areas, is to make a brighter signal return in the near-range than in the far-range, even after appropriate scattering-area calibration (van Zyl, 1993; van Zyl et al., 1993). Thus, although cross-correlation between JERS and ERS data was very successful in geometrically matching the scenes, where the far-range of one track was united to the near-range of another track within one ERS reference frame, the difference in image brightness along the image edges became very apparent.

While the SIBERIA philosophy was to avoid scene-to-scene radiometric enhancements prior to classification, this was not appropriate for the JERS mosaics within the ERS reference frames serving as reference units for the classification. Thus the JERS striping effect was compensated for by linearly transforming the backscatter intensity of the image with lesser coverage of the frame such that the tenth and ninetieth percentiles of the histograms (within the overlap areas only) were matched to those of the image with the greater frame coverage. A similar procedure was adopted for those ERS frames encompassing three JERS tracks and the effect was a seamless mosaicing of JERS data within the ERS reference frame system (Fig. 4). The remaining frame-to-frame variability in Fig. 4 is due to local effects which the classifier is designed to adapt to. This radiometric matching technique was achieved entirely automatically and, as well as enhancing the interpretability of the images, also improved the subsequent automatic classification of the multi-frequency composite.

$$
<\text { Insert Fig. } 4 \text { about here >> }
$$

At this stage in the processing, the complete image database consisted of 122 frames defined by the standard ERS reference system consisting of co-registered tandem coherence and fully calibrated JERS and ERS backscatter data. Only where this complete data stack was available, the pixels within the frame were passed on to the next step in the processing chain 
285 (otherwise the data was labeled as missing). These multi-band, frame-based data stacks are 286 used as input to the forest classification procedure.

\section{$287 \quad 4.4 . \quad$ Topographic Mask}

288 Over mountainous areas, topography may cause strong radiometric and geometric distortions 289 of the radar images which are not corrected for by the procedures described above. One problem is that ERS-GEC and JERS images are not radiometrically corrected with respect to topography, another one that terrain-induced distortions can make the co-registration of JERS

to ERS images significantly inaccurate. Therefore it was decided to mask areas of strong topography to avoid propagating these errors onwards. A masking procedure based on the

294 GTOPO30 DEM was developed and works as follows:

1. Resample (by nearest-neighbour) the GTOPO30 DEM to 50 x $50 \mathrm{~m}$ pixel spacing and generate a subset corresponding to the area of the respective ERS frame.

2. Calculate a geocoded incidence angle mask (GIM) based on the resampled GTOPO30 DEM and the ERS acquisition geometry for each frame.

3. Calculate the standard deviation of the local incidence angles for sub-areas of the GIM of a specific size (e.g. $10 \times 10$ pixels of $50 \times 50 \mathrm{~m}$ )

4. Apply a threshold to this standard deviation to mask out hilly terrain. The lower the threshold, the stronger is the masking.

Visual comparisons with backscatter images showed that a threshold of $1.4^{\circ}$ and a window size of 20 x 20 pixels lead to the best qualitative results for masking relief. 


\section{Exploratory Analysis}

306

\subsection{Growing Stock Volume}

An exploratory analysis of the forest and SAR databases was carried out over individual test sites to a) better understand the properties of the forest data base; b) identify the most relevant forest and radar parameters; c) investigate the dependence of radar parameters on forest properties and environmental effects; and to d) test forest classification methods. Results of this exploratory analysis were e.g. reported in Schmullius et al. (1999), Tansey et al. (1999), Wagner et al. (2000a), Gaveau et al. (2000) and Quegan et al. (2000b). An important finding was that the emphasis should be put on growing stock volume because a) it is the most valuable parameter in national forest inventories and for planning forest enterprise operations; and b) compared to other parameters collected by the Russian forest inventory, growing stock volume appears to be the one most directly related to the radar parameters. In general, growing stock volume as defined in the Russion forest inventory is the stem volume for all living species in a forest stand (unit is $\mathrm{m}^{3} / \mathrm{ha}$ ). However, only in young stands all stems are considered. In all other stands, to be included in the growing stock, trees must have trunk diameters greater or equal to $6 \mathrm{~cm}$ at breast height $(1.3 \mathrm{~m})$.

In agreement with conclusions of other studies (Section 2), the results of the exploratory analysis confirmed that, with respect to forest stem volume, the order of information content in the three available radar data channels was: best ERS coherence, second JERS backscatter, and last ERS backscatter. Therefore, subsequent research to make the crucial step from individual test areas to the entire SIBERIA area (i.e. to identify common behavior for all test areas), focused on the ERS coherence and the JERS intensity and their dependence on growing stock volume. The effect of tree species composition on this relationship appeared to be small and was not further investigated within the framework of this study. Nevertheless, future studies shall investigate the effect of species composition in more detail as it has been 
shown that the retrieval accuracy can be improved by taking forest structural effects into account (Dobson et al., 1995). The emphasis of the following discussion is on the ERS coherence and, to a lesser extent, on the JERS backscatter data.

\subsection{ERS Coherence}

Images and mosaics of the tandem coherence such as the one in Fig. 2 show the wealth of information carried by this parameter. Landscape and land-use features like river beds, agricultural land, or forest boundaries can be clearly distinguished at the maximum spatial resolution $(50 \mathrm{~m})$. Over gently sloping terrain topographic effects are hardly visible. As has already been observed by Wegmüller and Werner (1995), the coherence is less impacted by topography than the backscattering coefficient. However, over mountainous areas, the coherence images are also heavily influenced by topography.

As a result of temporal decorrelation, weather conditions have a strong impact on the coherence. Melting snow (Smith et al., 1998) or rainfall between acquisitions (Santoro et al., 2002) may lead to very low coherence values independent of land cover. In Fig. 2, such areas of very low coherence can be observed. These areas exhibit less spatial structure as revealed by a visual comparison with neighboring ERS tracks. To analyse environmental effects in these data, 3-hourly temperature and 12-hourly rainfall measurements from 113 stations spread over the area were acquired. Unfortunately, gaps in these data did not allow weather conditions to be checked for every satellite overflight. Table 2 shows temperature values and rainfall values for 13 (out of 18) ERS tracks of the SIBERIA area. Also given are orbits and dates for the respective ERS-1/2 acquisitions and the WMO number and coordinates of the meteorological station. Stations within a distance of $50 \mathrm{~km}$ to the left and right of the satellite track are shown. To get a best estimate of the temperature during the overflight times (UTC time of satellite passes are between UTC 3:00 and 5:00 depending on the geographic coordinates), temperature readings at UTC 3:00 and 6:00 of the respective days were 
averaged. Rainfall was estimated as the sum of the 12 hourly values reported at UTC 0:00 and 12:00, representing total rainfall within the period 16 hours before and 8 hours after data take. As can be seen in Table 2, temperatures were mostly well above $0^{\circ} \mathrm{C}$, even close to the end of the acquisition campaign in mid October. Therefore, it is unlikely that there was snow on the ground or that the ground was frozen. The rainfall data show that three tracks in particular were affected by rain: tracks 405, 104 and 147. These three tracks correspond to low coherence stripes in the mosaic (Fig. 2). This confirms that rainfall before and in-between ERS-1/2 tandem acquisitions can result in a significant loss of correlation. It would have been most appropriate in the case of the SIBERIA study to substitute these affected tracks with data from another time period. The temporary deployment of the DLR ground receiving station in Ulaanbaatar, however, prevented this. Therefore results from these three tracks should be treated with more caution than the remaining data.

$$
<\text { Insert Table } 2 \text { about here >> }
$$

To study the dependence of the coherence $(\gamma)$ on growing stock volume $(v)$, scatterplots of $\gamma$ versus $v$ were produced for individual test areas (Fig. 5). The coherence values were calculated by averaging over all pixels within each of the forest polygons. On average, forest polygons have a size of 36 ha (Section 3.2). After shrinking by two $50 \mathrm{~m}$ pixel to reduce border effects, their average size decreases to about 16 ha. This means that, on average, 64 pixel values were used to determine mean coherence values per forest inventory unit.

$$
<\text { Insert Fig. } 5 \text { about here }>>
$$

Even though the scattering of the data is large it can generally be observed that $\gamma$ is high for low stem volumes and decreases with increasing $v$ until a saturation threshold is reached (Fig. 5a to Fig. 5d). In many scatterplots, such as in Fig. 5d, extreme outliers with high $\gamma$ values are observed. Many such outliers were reported to the Russian forestry experts who verified that 
the database from which the $v$ values were taken was in error (recent clear cuts or forest fires had not been recorded). There are also testsites where the behavior described above is not or only weakly present. For example Fig. 5e, which shows data from a mountainous area near the southern end of Lake Baikal, demonstrates that topography causes a large scatter of $\gamma$ values. In other cases, where rainfall resulted in a loss of the coherence, no relationship between $\gamma$ versus $v$ can be discerned (Fig. 5f).

Over test areas where scattering is small, an exponential function can be used to describe the saturating behavior of $\gamma$ with increasing $v$. Depending on how the saturation point is defined, it is somewhere in the range 150 to $300 \mathrm{~m}^{3} / \mathrm{ha}$, but due to the high degree of scatter a retrieval of classes above about $100 \mathrm{~m}^{3} / \mathrm{ha}$ appears unrealistic. It is noted that other studies showed that a retrieval is possible up to $350-400 \mathrm{~m}^{3} / \mathrm{ha}$ (Smith et al., 1998; Santoro et al., 2002). The important difference is that these studies had access to multi-temporal ERS tandem acquisitions, also from the winter period when temporal decorrelation effects are minimal due to frost. Also, a linear model as used by Smith et al. (1998) and Koskinen et al. (2001) would not properly reflect the behavior seen in the scatter plots in Fig. 5a-d. Therefore it was proposed to use following empirical expression (Wagner et al., 2000b):

$$
\gamma(v)=\gamma_{\infty}+\left(\gamma_{0}-\gamma_{\infty}\right) \cdot e^{-\frac{v}{V_{\gamma}}}
$$

where $\gamma_{0}$ is the coherence at $v=0 \mathrm{~m}^{3} / \mathrm{ha}, \gamma_{\infty}$ the coherence for asymptotic values of $v$, and $V_{\gamma}$ is a characteristic stem volume where the exponential function has decreased by $e^{-1}$. The physical interpretation is that $\gamma_{0}$ represents typical coherence in non-forest areas and $\gamma_{\infty}$ that in dense forest. The parameter $V_{\gamma}$ determines how quickly saturation is reached. Due to the high scatter, the uncertainty range of the model parameters is large when Eq. (1) is fitted to training data sets based on individual test areas. By fixing the parameter $V_{\varkappa}$ the uncertainty intervals 
of $\gamma_{0}$ and $\gamma_{\infty}$ become smaller while the residual errors remain practically unchanged. This shows that $V_{\gamma}$ may be treated, in a first approximation, as a constant. On the other hand, $\gamma_{0}$ and $\gamma_{\infty}$ are highly variable from site to site. This is demonstrated by Fig. 6 which shows the relationship between $\gamma_{0}$ and $\gamma_{\infty}$ derived from 42 training data sets by fitting model (1) with $V_{\gamma}$ set equal to $100 \mathrm{~m}^{3} /$ ha (based on 33 test areas; 9 test areas were covered to a varying extent by a second ERS frame from a neighbouring track, thus giving more examples of coherence data). One can see that both parameters vary over large ranges: $\gamma_{0}$ between about 0.2 and 0.8 , and $\gamma_{\infty}$ between about 0.15 and 0.55 . It is also observed that $\gamma_{0}$ and $\gamma_{\infty}$ are correlated to some extent $\left(\mathrm{R}^{2}=0.54\right)$. This means that the coherence of non-forest areas tends to be larger in images where also the coherence of dense forest is large.

$$
<\text { Insert Fig. } 6 \text { about here >> }
$$

\subsection{JERS Backscatter}

The analysis of the JERS summer 1998 data followed in principle the same scheme as for the ERS coherence. Overall, our observations are in good agreement with findings reported in the literature (Section 2). As in the case of the coherence, the JERS mosaic (radiometrically adjusted only to match multiple JERS frames within each ERS frame) shows radiometric differences between ERS image frames (Fig. 4). These effects can be attributed to variable target conditions related to soil and vegetation moisture content. The scatterplots of the JERS backscattering coefficient $\sigma^{0}$ versus the growing stock volume $v$ exhibit an even larger scatter than is the case for the coherence. Nevertheless, the expected increase of $\sigma^{0}$ for low $v$ values and the saturation effect can be discerned for many testsites (e.g. Fig. 7). In some test areas, $\sigma^{0}$ remains rather stable over the range, but it was never observed to decrease with $v$ as can be the case for ERS SAR measurements over boreal forests (Kurvonen et al., 1999). 


\section{Mapping of Growing Stock Volume Classes}

\subsection{Classification Method}

The high degree of scattering of $\gamma$ and $\sigma^{0}$ for a given growing stock volume is due to many factors, including tree species composition, understory vegetation, ground conditions, topography, and environmental conditions (as well as remaining errors in the validation data). Therefore it was decided to rank growing stock volume by broad classes. The saturation effect observed in both $\gamma$ and L-band $\sigma^{0}$ limit the number of meaningful classes to a few low biomass forest classes and a "dense" forest class that comprises all forests with growing stock volumes above a threshold. The following forest classes were finally selected: $0-20,20-50$, 50-80, and $>80 \mathrm{~m}^{3} /$ ha based on the exploratory analyses described earlier and the requirements of the Russian forestry service partners.

The analysis of image histograms lead to the definition of two further classes: "water" and "smooth surface". The "smooth surface" class comprises areas of typically short vegetation cover like grassland, cultivated areas or bogs. A two-dimensional histogram plot of $\gamma$ and $\sigma^{0}$ can be seen in Fig. 8. This plot uses a cyclic colour scheme to visually indicate the relative frequency distribution within this particular frame. The water class is represented by the cluster around $\gamma=0.15$ and $\sigma^{0}=-15 \mathrm{~dB}$, smooth surfaces by the cluster around $\gamma=0.82$ and $\sigma^{0}=-13 \mathrm{~dB}$. The large cigar-shaped cluster represents the complete forest class. It has a frequency maximum in the lower $\gamma$ and higher $\sigma^{0}$ range. The analysis of the 122 histograms (representing the 122 ERS frames) shows that these three clusters can repeatedly be observed. While the classes "water" and "smooth surface" are remarkably stable, the width of the forest cluster varies substantially from frame to frame. 
The principal question is how to separate the large forest cluster into the four growing stock volume classes? For satellite images which cover test areas for which ground data is well known within the project, a straight forward approach would be to determine the class statistics for each of the four forest classes based on training data and use these as input into a maximum likelihood (ML) classifier. However, even though the test areas are well distributed within the SIBERIA project area the majority of the satellite frames could not be classified using in-situ data. Therefore, an alternative approach was adopted using generalized signatures derived by aggregating statistics from several test areas as input into a ML classifier. This approach was tested by Gaveau et al. (in press) who used training data from weighted $\kappa$-coefficient of 0.69 .

These results demonstrate that an approach involving a predetermined set of forest classes and class statistics, in combination with a simple ML classifier is viable. However, the limitations of using static signatures becomes clear when they are applied to all 122 satellite frames as the resulting mosaic shows major border effects. In fact, an important criterion for a classifier is that the results for adjacent images should be identical in the overlap area. If this criterion is nearly fulfilled, border effects are minimal and one can be assured that the classes are spatially consistent. Therefore, our goal was to improve the ML classifier by using frame 470 dependent estimates of the center values $\left(\gamma, \sigma^{0}\right)$ of the forest classes. These estimates are 471 driven by parameters of the $\gamma$ and $\sigma^{0}$ histograms which are derived from the images 472 themselves, i.e. the method is self-sufficient (Sections 6.2 and 6.3). Since the "water" and "smooth surface" class are comparably stable, their center values can be kept constant. 


\subsection{Histogram Analysis}

475

To investigate the properties of the image histograms, and in particular the structure of the forest cluster, one-dimensional image histograms of $\gamma$ and $\sigma^{0}$ are compared to histograms of the four forest classes $0-20,20-50,50-80$, and $>80 \mathrm{~m}^{3} /$ ha. Fig. 9 shows image histograms of the five satellite frames covering parts of the test territories Bolshe-Murtinsky, NizhneUdinsky, Chunksy, Primorsky, and Ulkansky (Fig. 1, Table 4). Open water surfaces were masked out for the purpose of this analysis. The total contributing inventory area, after shrinking of the forest polygons to account for registration errors, covered by each image ranges from 13,500 to 41,000 ha, corresponding to 1.3 to $4.1 \%$ of the imaged area. The relatively small area percentages implies that the forest classes may not always be representative of the entire image. This is particularly true for the three low stem volume classes which, in some cases, exhibit multi-modal histograms. In all cases, the dense forest class covers more than $57 \%$ of the testsite area (Table 4$)$. The $0-20 \mathrm{~m}^{3} /$ ha class is the second most frequent class, occupying up to $39 \%$. The abundance of the $>80 \mathrm{~m}^{3} /$ ha class stems from the fact that it covers about three-quarters of the possible growing stock range. As a result, it is reasonably to assume a priori for each satellite frame that the dense forest class is the dominating forest class.

$$
\begin{aligned}
& \text { < Insert Table } 4 \text { about here }>> \\
& <\text { Insert Fig. } 9 \text { about here }>>
\end{aligned}
$$

For the discussion of the $\gamma$ histograms let us consider Bolshe-Murtinsky as an example (Fig. 9 top-left). The coherence histogram shows two peaks, one around 0.3 corresponding to the frequency maximum within the forest cluster and one around 0.8 representing agriculture/grassland. Within the forest class, the $>80 \mathrm{~m}^{3} /$ ha class is the dominating class which finds its expression in the fact that the steep ascent from about 0.1 to 0.3 and the peak around 0.3 visible in the image histogram correspond well to the ascent and peak of the $>80$ 
$\mathrm{m}^{3} /$ ha class histogram. Comparing the image histograms of the other four test territories with Bolshe-Murtinsky, one can observe that there is less agriculture/grassland and that the position of the forest peak may be shifted towards lower ( 0.23 for Ulkansky) and higher ( 0.36 for Primorsky) $\gamma$ values. Nevertheless, the ascents and peaks of the image histograms can reasonably be explained by the $>80 \mathrm{~m}^{3} /$ ha class histograms. To quantify the position of the ascent let us define a parameter $\gamma_{H}$ as being that $\gamma$ value where the image histogram reaches $75 \%$ of the forest peak. For our five training data sets $\gamma_{H}$ is highly correlated with the median value of the dense forest class $\left(\mathrm{R}^{2}=0.88\right)$. This finding is motivation to use $\gamma_{H}$ as input into a simple empirical model to estimate the class centers of growing stock volume classes (Section $6.3)$.

Compared to the $\gamma$ histograms, the succession of the classes is transposed in the case of $\sigma^{0}$. Agriculture/grassland influences the shape of the image histogram at low $\sigma^{0}$ values, followed by the forest classes $0-20,20-50$, and $50-80 \mathrm{~m}^{3} /$ ha. For high $\sigma^{0}$ values the image histograms are dominated by the $>80 \mathrm{~m}^{3} /$ ha class which determines the position of the descending flank. The histogram peaks appears to be shifted by a few tenths of a $\mathrm{dB}$ towards lower $\sigma^{0}$ values compared to the peaks of the dense forest class. Similar to $\gamma_{H}$ let us define a parameter $\sigma_{H}$ as being those $\sigma^{0}$ value where the image histogram reaches $75 \%$ of the dense forest peak, approaching the peak from the right hand side. The correlation of $\sigma_{H}$ and the median $\sigma^{0}$ value of the dense forest class is $\mathrm{R}^{2}=0.85$.

The importance of the dense forest class for explaining the image histograms is a consequence of the quick saturation of both $\gamma$ and $\sigma^{0}$ within increasing growing stock volume. In the following, the histogram parameters $\gamma_{H}$ and $\sigma_{H}$ are used to drive empirical models to estimate the position of the forest classes in the two-dimensional $\left(\gamma, \sigma^{0}\right)$ space. 


\subsection{Estimation of Class Centres}

For the development of a model to estimate the centers of the four forest classes, we use again the training data set given by Table 4 . In a first step, the class centers are estimated based on the forest inventory data. As can be observed in Fig. 9, some of the forest class histograms are slightly skewed or even exhibit multiple modes. Nevertheless, it is assumed that the class distributions for the larger samples are approximately Gaussian; their centers are estimated by calculating the median values of the histograms shown in Fig. 9. The resulting coherence values for the five test territories are displayed in Fig. 10, JERS intensity data in Fig. 12.

For formulating a coherence model, let us recall the exponential model discussed in Section 5.2 and that $\gamma_{H}$ is well correlated to the center of the dense forest class. Let us rewrite Eq. (1)

$$
\gamma(v)=\gamma_{H}+a_{\gamma} \cdot e^{-\frac{v}{V_{\gamma}}} \quad \text { Model I }
$$

where $\gamma_{0}$ was substituted by $\gamma_{H}$, and the term $\left(\gamma_{0}-\gamma_{\infty}\right)$ by the parameter $a_{\gamma}$ representing the dynamic range. In this model, $\gamma_{H}$ is the only input variable which can shift the absolute level from frame to frame, while $a_{\gamma}$ and $V_{\gamma}$ are fixed model parameters which are derived based on training data. Since the dynamic range appears to increase slightly with the overall coherence level, an alternative model is formulated:

$$
\gamma(v)=\gamma_{H}+\left(a_{\gamma}+b_{\gamma} \cdot \gamma_{H}\right) \cdot e^{-\frac{v}{V_{\gamma}}} \quad \text { Model II }
$$

where the role of the model parameter $b_{\gamma}$ is to modulate the dynamic range. Fitting the models to the five training data sets individually indicates the parameter ranges. For the fit, the values $v=10,35,65$ and $200 \mathrm{~m}^{3} /$ ha are used to represent the classes $0-20,20-50,50-80$ and $>80$ $\mathrm{m}^{3} /$ ha. Using Model I, the parameter $a_{\gamma}$ ranges between 0.34 and 0.61 and $V_{\gamma}$ between 94.3 and $145.5 \mathrm{~m}^{3} /$ ha. Nevertheless, for the production of the mosaic one set of parameters is needed which is why Eq. (2) and (3) were fitted to all five training data sets concurrently: 


$$
\gamma(v)=\gamma_{H}+0.457 \cdot e^{-\frac{v}{122.1}} \quad \text { Model I }
$$

$$
\gamma(v)=\gamma_{H}+\left(0.33+0.581 \cdot \gamma_{H}\right) \cdot e^{-\frac{v}{122.1}} \quad \text { Model II }
$$

547 The resulting fit of Model II for the five territories is also shown in Fig. 10. One can see that the general trend is well reflected, but for individual training data sets (e.g. Bolshe-Murtinsky) the deviations may be substantial. In general, both models perform well for the dense forest class but less so for the low biomass classes: the standard deviation of the residuals for the $>80 \mathrm{~m}^{3} /$ ha class is in the order of 0.02 , for the $20-50$ and $50-80 \mathrm{~m}^{3} /$ ha classes 0.06 and for the 0-20 $\mathrm{m}^{3} /$ ha class 0.09 . In Fig. 11, $\gamma$ of the four forest classes estimated with models (4) and (5) is plotted versus the histogram parameter $\gamma_{H}$, which were extracted from the 122 coherence images. Also, the peaks of the image histograms are shown. One can see that, except for a few outliers, the histogram peaks and the simulated $\gamma$ value of the $>80 \mathrm{~m}^{3} /$ ha class agree well for both models, which is consistent with our observations over the five test territories. For the low biomass classes Model II varies more strongly with $\gamma_{H}$ compared to Model I. Both models were used to produce classified mosaics of the entire area. Since this showed that the use of Model II improved the agreement of the classification in the overlap areas of adjacent images, 560 it was finally chosen.

563 Similarly, exponential models are postulated for the JERS backscattering coefficient to describe the saturation effect and fitted to the training data from the five test territories concurrently (Fig. 12): 


$$
\sigma^{0}(v)=\sigma_{H}-\left(3.07+1.06 \cdot \sigma_{H}\right) \cdot e^{-\frac{v}{106.1}} \quad \text { Model II }
$$

568 As was the case for $\gamma$, the standard deviation of the residuals is low for the dense forest class

569 (0.22 dB for Model I and $0.25 \mathrm{~dB}$ for Model II) but higher for the low stem volume classes $570(0.49-0.79 \mathrm{~dB})$. The comparison of the models with the observed histogram peaks (Fig. 13)

571 shows that the peak is shifted by about $0.2-0.7 \mathrm{~dB}$ towards lower $\sigma^{0}$ values compared to the

572 modeled $\sigma^{0}$ of the $>80 \mathrm{~m}^{3} /$ ha class, which again is consistent with the findings of the 573 histogram analysis. Because the relatively large dynamic range of Model II appeared 574 unrealistic, Model I was selected.

<< Insert Fig. 12 about here >>

$<<$ Insert Fig. 13 about here $>>$

\subsection{Properties of Forest Map}

To arrive at the forest map for the entire SIBERIA project area, the following processing and classification steps are applied:

1. Interferometric processing of the ERS tandem data from fall 1997, including DEM generation and geometric correction (Sections 3.3 and 4.1);

2. JERS geometric and radiometric matching to bring the JERS data into the ERS standard frame system (Sections 3.3, 4.2 and 4.3);

3. Masking of areas of strong topography (Section 4.4);

4. Determination of histogram parameters $\gamma_{H}$ and $\sigma_{H}$ for each satellite frame (after removing of water surfaces by simple thresholding);

5. Application of a maximum likelihood algorithm which uses as input the class statistics given in Table 5; 
6. Application of an Iterated Contextual Probability (IPC) algorithm (Balzter et al., in press) to improve the image context;

7. Mosaicing of classified satellite frames.

\section{$<<$ Insert Table 5 about here $>>$}

The resulting forest map (Fig. 14) shows that, for the major part of the study area, the classified maps merge nicely with the neighboring images. The notable exception are those satellite tracks where the coherence was affected by rain, such as track 405 . A comparison of the ERS and JERS data shows that some clear-cut areas visible in the JERS backscatter data are not observed in the corresponding coherence image. Therefore, in the situation when rainfall caused a loss of coherence, most of the information in the classified map stems from the JERS image. Still, the dense forest class is still overestimated in these cases. Nevertheless, the consistency of the results for the majority of the study area is demonstration of the viability of the chosen approach. The method worked not only in regions dominated by forests but also in areas where forested land occupies only a small faction of the land.

\section{$<<$ Insert Fig. 14 about here $>>$}

The methods and results of the accuracy assessment are described in detail in Balzter et al. (in press). This papers also discusses the inherent uncertainties in the inventory data and how these affect the accuracy assessment. To quantify the agreement of the classified map to the reference data, a weighted $\kappa_{w}$ coefficient of agreement was calculated. A comparison of the classified map with the data from the Russian forest inventory shows a reasonable agreement of the $0-20$ and $>80 \mathrm{~m}^{3} /$ ha classes while for the two intermediate forest classes (20-50 and $50-80 \mathrm{~m}^{3} / \mathrm{ha}$ ) user and producer accuracies are low (generally much lower than $50 \%$ ). The resulting weighted $\kappa_{w}$ coefficient of agreement is 0.72 . As a second means to assess the quality of the map, Russian forestry experts carried out an a posteriori ground survey (GS) 
613

614

615

616

617

618

619

620

621

622

623

624

625

626

627

628

629

630

631

632

633

634

635

636

over seven test areas with the aim of achieving a more reliable accuracy statistics map. They used new aerial photography, optical images from other satellites and data collected directly in the field. The heterogeneity of forest inventory units was taken into account by identifying homogeneous patches within the inventory units. The pooled confusion matrixes for all GS sites is shown in Table 6 . The results of this assessment are surprisingly good with user and producer accuracies larger than $81 \%$ and $\kappa_{w}=0.94$.

$<$ Insert Table 6 about here $>>$

\section{Conclusions}

The SIBERIA project has demonstrated that large-scale mapping of growing stock volume up to about $80 \mathrm{~m}^{3} / \mathrm{ha}$ is possible over boreal forest using ERS-1/2 tandem data from fall 1997 (unfrozen conditions) and JERS backscatter data from summer 1998, except for areas where topography causes strong distortions of the radar images. In particular, the ERS tandem coherence (one-day repeat pass) provides valuable information if rainfall shortly before or inbetween the tandem acquisitions does not lead to a loss of interferometric coherence.

The forest map was produced by classifying individual satellite images and by mosaicing the resulting map. One advantage of this approach is that the spatial consistency of the results can be checked by comparing the classification results in overlap zones of adjacent images. The classification rests on a standard maximum likelihood algorithm which uses class statistics based on the training data to classify two-dimensional images of the ERS tandem coherence and JERS intensity. The class centers of four growing stock volume classes (0-20, 20-50, 50$80,>80 \mathrm{~m}^{3} / \mathrm{ha}$ ) are estimated for each satellite frame individually. The method rests on empirical models which describe the dependence of the tandem coherence and the JERS backscattering coefficient on growing stock volume and on parameters derived from the image histograms. The models are very simple and do not explicitly model the effect of soil 
637 moisture, tree species composition, understory vegetation or other important effects. 638 Implicitly, some of these effects are taken into account by using histogram parameters as 639 input into these models, which are themselves a surrogate for these effects. The limitations 640 inherent to an empirical approach must be clearly recognized: it is generally only valid under 641 the special conditions for which it was developed (e.g. the coherence model may only be valid 642 for fall tandem acquisitions of boreal forest under non-frozen conditions) and is generally only suited for the targeted application (i.e. providing first-order estimates of center values of 644 four broad stem volume classes). For our study area the approach worked surprisingly well as 645 the rather homogeneous classification result for over 100 ERS image frames covering 646 approximately 1 million $\mathrm{km}^{2}$ and accuracies above $80 \%$ illustrate.

647 Due to the low saturation level the data are at first sight of limited use for forest management 648 applications, even for Siberia. However, it must be considered that a major part of the Russian 649 forest inventory data are obsolete: they have been collected 10-30 years ago. (Currently 650 Russia provides forest inventory on about 25-30 million ha annually. This means that for the total Russian forest fund area of 1.18 billion ha about 40 years are needed to cover the entire 652 territory by the forest inventory.) Due to high reliability of the SAR identification of areas with small biomass (burnt and harvested areas) the technique offers (for Siberia) unique possibilities to update existing inventory data and characterizing 1) level of disturbances and their consequences, 2) succession regularities, 3) restoration processes in forests, and 4) current state of forests.

The results reported in this paper present only a first step towards a comprehensive analysis of 658 the rich database built up during the SIBERIA project. Further studies will analyze the 659 influence of other forest parameters (tree species composition, age, etc) in a more comprehensive way. Also, future studies should investigate the use of emerging, more physically based methods for improving the empirical approach presented here. 


\section{Acknowledgements}

This study was funded by the Environment and Climate Program of the European Commission (ENV4-CT98-0743). Data was generously supplied by ESA (through the third ERS announcement of opportunity - AO3-120) and NASDA (through the global boreal forest monitoring initiative - GBFM, with particular thanks to Dr. Shimada). ERS SAR and interferometric processing was carried out by DLR-DFD, Germany and JERS SAR processing and interferometry by GAMMA RS, Switzerland (SIBERIA data set). The satellite data were received by a mobile receiving station of the German Remote Sensing Data Centre of DLR (DFD), which was deployed for this purpose in Ulaanbaatar, Mongolia. We are indebted to all colleagues who worked with us on the SIBERIA project: Victor Skudon, Leonid Vaschuk, Vladimir Sokolov, Vjacheslav Rozhkov, Leif Eriksson, Andrea Holz, Hans Jonsson, Ursula Marschalk, Ian McCallum, Sten Nilsson, Alf Oeskog, Marianne Orrmalm, Steve Plummer, Yrjo Rauste, Achim Roth, Roland Utsi, Urs Wegmüller, and Torbjorn Westin. 


\section{References}

Askne, J. I. H., and Smith, G. (1996), Forest INSAR decorrelation and classification properties. In ESA Fringe 96 Workshop on ERS SAR Interferometry, Zurich, Switzerland, 30 September-2 October, ESA: SP406, 95-103.

Askne, J. I. H., Dammert, P. B. G., Ulander, L. M. H., and Smith, G. (1997), C-band repeatpass interferometric SAR observation of the forest. IEEE Trans. Geosci. Remote Sens. $35: 25-35$.

Balzter, H. (2001), Forest mapping and monitoring with interferometric synthetic aperture radar (InSAR). Progress in Physical Geography 25:159-177.

Balzter, H., Talmon, E., Wagner, W., Gaveau, D., Plummer, S., Yu, J. J., Quegan, S., Gluck, M., Shvidenko, A., Tansey, K., Luckman, A., and Schmullius, C. (2002), Accuracy assessment of a large-scale forest map of central Siberia from Synthetic Aperture Radar. Can. J. Remote Sens., in press.

Castel, T., Guerra, F., Caraglio, Y., and Houllier, F. (2002), Retrieval biomass of a large Venezuelan pine plantation using JERS-1 SAR data. Analysis of forest structure impact on radar signature. Remote Sens. Environ. 79:30-41.

De Grandi, G. F., Mayuax, P., Malingreau, J. P., Baraldi, A., Simard, M., and Saatchi, S. (2002), Cornerstones and epilogue of the GRFM Africa Project: a Gallery of Regional Scale Vegetation Maps. In Proceedings of IGARSS'02 Conference, Toronto, Canada, 2428 June.

De Grandi, G., Mayaux, P., Rauste, Y., Rosenqvist, A., Simand, M., and Saatchi, S. (2000), The Global Rain Forest Mapping Project JERS-1 radar mosaic of tropical Africa: Development and product characterization aspects. IEEE Trans. Geosci. Remote Sens. 
$38: 2218-2233$.

Dobson, M. C., Ulaby, F. T., Pierce, L. E., Sharik, T. L., Bergen, K. M., Kellndorfer, J., Kendra, J. R., Li, E., Lin, Y. C., Nashashibi, A., Sarabandi, K., and Siqueira, P. (1995) Estimation of forest biophysical characteristics in Northern Michigan with SIR-C/X-SAR. IEEE Trans. Geosci. Remote Sens. 33(4): 877-895.

Fransson, J. E. S., and Israelsson, H. (1999), Estimation of stem volume in boreal forests using ERS-1 C- and JERS-1 L-band SAR data. Int. J. Remote Sens. 20 :123-137.

Gaveau D. L. A. (2002), Modelling the dynamics of ERS-1/2 coherence with increasing woody biomass over boreal forest. Int. J. Remote Sens., 23(18): 3879-3885.

Gaveau, D. L. A., Balzter, H., and Plummer, S. (2000), Boreal forest InSAR classification properties. In Proceedings of the CEOS SAR Workshop, Toulouse, France, 26-29 October, ESA SP-450, pp. 509-512.

Gaveau, D. L. A., Balzter, H., and Plummer, S. (2002), Forest woody biomass classification with satellite-based radar coherence over $900000 \mathrm{~km}^{2}$ in Central Siberia. Forest Ecology and Management, in press.

Hagberg, J. O., Ulander, L. M. H., and Askne, J. (1995), Repeat-pass SAR interferometry over forested terrain. IEEE Trans. Geosci. Remote Sens. 33 :331-339.

Hyyppä, J., Hyyppä, H., Inkinen, M., Engdahl, M., Linko, S., and Zhu, Y.-H. (2000), Accuracy comparison of various remote sensing data sources in the retrieval of forest stand attributes. Forest Ecology and Management, 128:109-120.

Imhoff, M. L. (1995), Radar backscatter and biomass saturation: Ramifications for global biomass inventory, IEEE Trans. Geosci. Remote Sens. 23(2):511-518.

Koskinen, J. T., Pulliainen, J. T., Hyyppä, J. M., Engdahl, M. E., and Hallikainen, M. T. 
(2001), The seasonal behaviour of interferometric coherence in boreal forest. IEEE Trans. Geosci. Remote Sens. 39 :820-829.

Kuplich, T. M., Salvatori, V., and Curran, P. J. (2000), JERS-1/SAR backscatter and its relationship with biomass of regenerating forest. Int. J. Remote Sens. 21 :2513-2518.

Kurvonen, L., Pulliainen, J., and Hallikainen, M. (1999), Retrieval of biomass in boreal forest from multitemporal ERS-1 and JERS-1 SAR images. IEEE Trans. Geosci. Remote Sens. $37: 198-205$.

Laur, H., Bally, P., Meadows, P., Sanchez, J., Schättler, B., Lopinto, E., and Esteban, D. (1998), ERS SAR Calibration: Derivation of sigma0 in ESA ERS SAR PRI Product. ESA/ESRIN, ES-TN-RS-PM-HL09, Issue 2, Rev. 5b, September 1998, ESA, Paris.

Le Toan, T., Picard, G., Martinez, J.-M., Melon, P., and Davidson, M. (2002), On the relationships between radar measurements and forest structure and biomass. In Proceedings of the $3^{\text {rd }}$ International Symposium on Retrieval of Bio- and Geophysical Parameters from SAR Data for Land Applications, Sheffield, UK, 11-14 September 2001, ESA SP-475, pp. 3-12.

Leckie, D. G., and Ranson, K. J. (1998), In Principles and Applications of Imaging Radars, Manual of Remote Sensing (Henderson, F. M., and Lewis, A. J., Eds., $3^{\text {rd }}$ Edition), John Wiley \& Sons, New York, pp. 435-509.

Luckman, A., Baker, J., Honsák, M., and Lucas, R. (1998), Tropical forest biomass estimation using JERS-1 SAR: Seasonal variation, confidence limits, and application to image mosaics. Remote Sens. Environ. 63:126-139.

Nilsson, S., and Shvidenko, A. (1998), Is sustainable development of the Russian forest sector possible? IUFRO Occasional Paper No. 11, ISSN 1024-414X, IUFRO Secretariat, Vienna, 
Austria, 76 pp.

Pulliainen, J. T., Kurvonen, L., and Hallikainen, M. T. (1999), Multitemporal behavior of Land C-band SAR observations of boreal forest. IEEE Trans. Geosci. Remote Sens. $37: 927-937$.

Pulliainen, J. T., Mikkelä, P. J., Hallikainen, M. T., and Ikonen, J.-P. (1996), Seasonal dynamics of C-band backscatter of boreal forests with applications to biomass and soil moisture estimation. IEEE Trans. Geosci. Remote Sens. 34 :758-769.

Quegan, S., Le Toan, T., Yu, J. J., Ribbes, F., and Floury, N. (2000a), Multitemporal ERS SAR analysis applied to forest mapping. IEEE Trans. Geosci. Remote Sens. 38 :741-753.

Quegan, S., Yu, J.J., Balzter, H., and LeToan, T. (2000b), Combining unsupervised and knowledge-based methods in large-scale forest classification. In Proceedings of IGARSS’2000 Conference, Honolulu, Hawaii, USA, 24-28 July, pp. 426 -428.

Rosenqvist, A., Shimada, M., Chapman, B., Freeman, A., De Grandi, G., Saatchi, S., and Rauste, Y. (2000), The Global Rain Forest Mapping Project - a review. Int. J. of Remote Sens. 21:1375-1387.

Roth, A, Knöpfle, W., Hubig M., and Adam, N. (1998), Operational interferometric SAR products. In Proceedings of IGARSS'98 Conference, Seattle, USA, 6-10 July.

Santoro, M., Askne, J., Smith, G., and Fransson, J. E. S. (2002), Stem volume retrieval in boreal forests from ERS-1/2 interferometry. Remote Sens. Environ. 81:19-35.

Santos, J. R., Pardi Lacruz, M. S., Araujo, L. S., and Keil, M. (2002), Savanna and tropical rainforest biomass estimation and spatialization using JERS-1 data. Int. J. Remote Sens. 23 :1217-1229.

Sarabandi, K., and Wilsen, C. B. (2000), Temporal decorrelation of vegetation by 
environmental and seasonal effects. In Proceedings of IGARSS'2000 Conference, Honolulu, Hawaii, USA, 24-28 July, pp. 1399-1401.

Schmullius, C. (Ed.) (2001), SIBERIA - SAR Imaging of Boreal Ecology and Radar Interferometry Applications. Final Report, European Commission, Co. No. ENV4-CT980743, $115 \mathrm{p}$.

Schmullius, C., and Rosenqvist, A. (1997), Closing the gap - a Siberian boreal forest map with ERS-1/2 and JERS-1. In Proceedings of the $3^{\text {rd }}$ ERS Symposium on Space at the Service of our Environment, Florence, Italy, 17-21 March, ESA SP-414, pp. 1885-1890.

Schmullius, C., Holz, A., and Vietmeier, J. (1999), SIBERIA - Results from the IGBP Boreal Forest Transect. In Proceedings of IGARSS'99 Conference, Hamburg, Germany, 28 June2 July, pp. 2118-2120.

Shimada, M. (1996), Radiometric and Geometric Calibration of JERS-1 SAR. Advanced Space Res. 17:79-88.

Smith, G., Dammert, P. B. G., Santoro, M., Fransson, J. E. S., Wegmüller, U., and Askne, J. (1998), Biomass retrieval in boreal forest using ERS and JERS SAR. In $2^{\text {nd }}$ International Workshop on Retrieval of Bio- and Geophysical Parameters from SAR data for Land Applications, Noordwijk, The Netherlands, pp. 293-300.

Strozzi, T., Dammert, P. B. G., Wegmüller, U., Martinez, J.-M., Askne, J. I. H., Beaudin, A., and Hallikainen, M. (2000), Landuse mapping with ERS SAR interferometry. IEEE Trans. Geosci. Remote Sens. 38 :766-775.

Tansey, K., Luckman, A. and Schmullius, C. (1999), Mapping boreal forest in Siberia with ERS SAR Interferometry. In Proceedings of the $25^{\text {th }}$ Annual Conference of the Remote Sensing Society (RSS 99), Cardiff, Wales, UK, 8-10 September. 
Teillet, P. M., Guidon, B., Meunier, J.-F., and Goodenough, D. G. (1985), Slope-aspect effects in synthetic aperture radar imagery. Can. J. Remote Sens. 11:39-49.

U.S. Geological Survey (1997), GTOPO30 Documentation. USGS, Sioux Falls, South Dakota, USA.

Ulaby, F. T., Sarabandi, K., McDonad, K., Witt, M., and Dobson, M. C. (1990), Michigan microwave scattering model. Int. J. Remote Sens. 11 :1223-1253.

Van Zyl, J. J. (1993), The effect of topography on radar scattering from vegetated areas. IEEE Trans. Geosci. Remote Sens. 31 :153-160.

Van Zyl, J. J., Chapman, B. D., Dubois, P., and Shi, J. (1993), The effect of topography on SAR calibration. IEEE Trans. Geosci. Remote Sens. 31 :1036-1043.

Wagner, W., Vietmeier, J., and Schmullius, C. (2000b), Information content of ERS SAR interferometric products for forest classification in SIBERIA: A case study over the Bolshe-murtinskii forest enterprise. In Proceedings of IGARSS'2000 Conference, Honolulu, Hawaii, USA, 24-28 July, pp. $444-446$.

Wagner, W., Vietmeier, J., Schmullius, C., Le Toan, T., Davidson, M., Quegan, S., Yu, J. J., Luckman, A., Tansey, K., Balzter, H., and Gaveau, D. (2000a), The use of coherence information derived from ERS tandem pairs for determining forest stock volume in SIBERIA. In Proceedings of IGARSS'2000 Conference, Honolulu, Hawaii, USA, 24-28 July, pp. 1396-1398.

Wegmüller, U., and Werner, C. L. (1995), SAR interferometric signatures of forest. IEEE Trans. Geosci. Remote Sens. 33 :1153-1161.

Wiesmann, A., Strozzi, T., and Wegmüller, U. (1999), JERS SAR processing for the boreal forest mapping project SIBERIA. In Proceedings of IGARSS'99 Conference, Hamburg, 
Germany, 28 June-2 July.

Zebker, H. A., and Villasenor, J. (1992), Decorrelation in interferometric radar echoes. IEEE Trans. Geosci. Remote Sens. 30 :950-959. 


\section{Tables}

Table 1: Test territories and test areas.

Table 2: Environmental conditions during ERS-1/2 tandem acquisitions. The first five rows show track and orbit/date for ERS-1 and ERS-2 respectively. The next columns list the WMO stations and their coordinates. Temperature values for the overflight times are given in degree Celsius (average of temperature at UTC 3:00 and 6:00). The last two columns show estimated rainfall in millimeters within 24 hours before acquisitions (sum of 12 hourly rainfall reported for UTC 0:00 and UTC 12:00). "noV" indicates missing values.

Table 3: Generalised coherence signatures used by Gaveau et al. (in press)

Table 4: Satellite data and testsites used for estimating model parameters. The first column shows the name of the forest enterprise. The second to forth columns give track, frame and acquisition dates of the ERS tandem pairs, the fifth column the JERS acquisition date. Then follows the total area of all testsites (after shrinking of polygons to account for co-registration errors) covered by the satellite data and finally, the area percentages for the four forest classes $0-20,20-50,50-80$, and $>80 \mathrm{~m}^{3} /$ ha.

Table 5: Class statistics used as input to a maximum likelihood algorithm. The coherence values for the four forest classes are determined according to Eq. (5) and the JERS backscatter values according to Eq. (6). $\gamma_{H}$ and $\sigma_{H}$ are histogram parameters (Section 6.2).

Table 6: Pooled confusion matrix for seven ground survey (GS) sites. Numbers are 1 ha (4 pixels) sample plots determined by Russian forestry experts. From Balzter et al. (in press). 


\begin{tabular}{|c|c|c|c|c|c|c|}
\hline \multirow{3}{*}{\begin{tabular}{|l} 
Territories \\
(Inventory Year)
\end{tabular}} & \multicolumn{6}{|c|}{ Test Area } \\
\hline & \multirow[t]{2}{*}{ No. } & \multicolumn{2}{|c|}{ Center Coordinates (deg) } & \multirow[t]{2}{*}{ Area (ha) } & \multirow{2}{*}{$\begin{array}{c}\text { No. of } \\
\text { Polygons }\end{array}$} & \multirow{2}{*}{$\begin{array}{l}\text { Avg. Poly. } \\
\text { Size (ha) }\end{array}$} \\
\hline & & Longitude & Latitude & & & \\
\hline $\begin{array}{l}\text { Bolshe-Murtinsky } \\
(1997)\end{array}$ & $\begin{array}{l}1 \\
2 \\
3 \\
4\end{array}$ & $\begin{array}{l}92.50 \\
93.79 \\
93.54 \\
92.16\end{array}$ & $\begin{array}{l}57.24 \\
57.20 \\
56.91 \\
56.91\end{array}$ & $\begin{array}{l}29543 \\
27552 \\
20918 \\
26721\end{array}$ & $\begin{array}{c}1263 \\
1606 \\
964 \\
547 \\
\end{array}$ & $\begin{array}{l}23 \\
17 \\
22 \\
49\end{array}$ \\
\hline Chunsky (1997) & $\begin{array}{l}1 \\
2 \\
3 \\
4 \\
5\end{array}$ & $\begin{array}{l}95.55 \\
96.75 \\
97.59 \\
96.35 \\
95.40\end{array}$ & $\begin{array}{l}58.00 \\
57.89 \\
57.85 \\
57.54 \\
57.79\end{array}$ & $\begin{array}{l}32192 \\
38918 \\
36552 \\
32500 \\
23654\end{array}$ & $\begin{array}{c}716 \\
1284 \\
1113 \\
915 \\
549\end{array}$ & $\begin{array}{l}45 \\
30 \\
33 \\
36 \\
43\end{array}$ \\
\hline Ermakovsky (1995) & $\begin{array}{l}1 \\
2 \\
3 \\
4\end{array}$ & $\begin{array}{l}93.20 \\
93.20 \\
92.26 \\
92.81 \\
\end{array}$ & $\begin{array}{l}53.18 \\
52.86 \\
52.96 \\
53.09\end{array}$ & $\begin{array}{l}19240 \\
20566 \\
18194 \\
17682 \\
\end{array}$ & $\begin{array}{l}767 \\
382 \\
808 \\
662 \\
\end{array}$ & $\begin{array}{l}25 \\
54 \\
23 \\
27\end{array}$ \\
\hline Hrebtovsky (1996) & $\begin{array}{l}1 \\
2 \\
3 \\
4\end{array}$ & $\begin{array}{l}99.74 \\
99.71 \\
98.36 \\
99.27\end{array}$ & $\begin{array}{l}59.99 \\
59.49 \\
58.63 \\
59.78\end{array}$ & $\begin{array}{l}50050 \\
28515 \\
33535 \\
29447\end{array}$ & $\begin{array}{c}1378 \\
867 \\
1042 \\
944\end{array}$ & $\begin{array}{l}36 \\
33 \\
32 \\
31\end{array}$ \\
\hline Irbeisky (1998) & $\begin{array}{l}1 \\
2 \\
3 \\
4 \\
5\end{array}$ & $\begin{array}{l}95.98 \\
96.54 \\
96.44 \\
96.05 \\
95.43\end{array}$ & $\begin{array}{l}55.57 \\
55.24 \\
54.64 \\
55.20 \\
55.39\end{array}$ & $\begin{array}{l}28090 \\
26389 \\
28446 \\
39541 \\
14094\end{array}$ & $\begin{array}{c}910 \\
850 \\
399 \\
1720 \\
1213\end{array}$ & $\begin{array}{l}31 \\
31 \\
71 \\
23 \\
12 \\
\end{array}$ \\
\hline $\begin{array}{l}\text { Juzhno-Baikalsky } \\
(1985, \text { updated 1997) }\end{array}$ & $\begin{array}{l}1 \\
2 \\
3\end{array}$ & $\begin{array}{l}103.31 \\
104.23 \\
104.50\end{array}$ & $\begin{array}{l}51.71 \\
51.48 \\
51.40\end{array}$ & $\begin{array}{c}11005 \\
6270 \\
13000\end{array}$ & $\begin{array}{l}738 \\
370 \\
870\end{array}$ & $\begin{array}{l}15 \\
17 \\
15\end{array}$ \\
\hline Mansky (1996) & $\begin{array}{l}1 \\
2 \\
3 \\
4\end{array}$ & $\begin{array}{l}93.36 \\
93.40 \\
93.81 \\
93.31\end{array}$ & $\begin{array}{l}55.47 \\
55.30 \\
55.28 \\
55.10\end{array}$ & $\begin{array}{c}41000 \\
2109 \\
41248 \\
58281\end{array}$ & $\begin{array}{c}1622 \\
99 \\
1304 \\
1906\end{array}$ & $\begin{array}{l}25 \\
21 \\
32 \\
31\end{array}$ \\
\hline $\begin{array}{l}\text { Nizhne-Udinsky } \\
(1997)\end{array}$ & $\begin{array}{l}1 \\
2 \\
3 \\
4\end{array}$ & $\begin{array}{c}100.08 \\
99.58 \\
97.61 \\
98.80 \\
\end{array}$ & $\begin{array}{l}55.40 \\
54.52 \\
54.00 \\
54.70\end{array}$ & $\begin{array}{l}51035 \\
25373 \\
73667 \\
29654 \\
\end{array}$ & $\begin{array}{c}1988 \\
907 \\
394 \\
1104\end{array}$ & $\begin{array}{c}26 \\
28 \\
187 \\
27\end{array}$ \\
\hline Primorsky (1997) & $\begin{array}{l}1 \\
2 \\
3 \\
4\end{array}$ & $\begin{array}{l}102.26 \\
102.54 \\
102.50 \\
102.07\end{array}$ & $\begin{array}{l}56.10 \\
55.77 \\
55.58 \\
55.74\end{array}$ & $\begin{array}{l}14859 \\
20760 \\
20156 \\
17871\end{array}$ & $\begin{array}{l}743 \\
992 \\
785 \\
709\end{array}$ & $\begin{array}{l}20 \\
21 \\
26 \\
25\end{array}$ \\
\hline $\begin{array}{l}\text { Sayano-Shushensky } \\
(1996)\end{array}$ & $\begin{array}{l}1 \\
2 \\
3 \\
4\end{array}$ & $\begin{array}{l}91.65 \\
92.21 \\
90.99 \\
91.62\end{array}$ & $\begin{array}{l}52.92 \\
52.77 \\
52.13 \\
52.64\end{array}$ & $\begin{array}{c}59682 \\
38309 \\
166341 \\
30000\end{array}$ & $\begin{array}{c}2369 \\
586 \\
1208 \\
424\end{array}$ & $\begin{array}{c}25 \\
65 \\
138 \\
71\end{array}$ \\
\hline Shestakovsky (1997) & $\begin{array}{l}1 \\
2 \\
3 \\
4\end{array}$ & $\begin{array}{l}103.47 \\
104.51 \\
104.26 \\
102.83\end{array}$ & $\begin{array}{l}56.67 \\
56.44 \\
56.10 \\
56.26\end{array}$ & $\begin{array}{l}20049 \\
32414 \\
41997 \\
28000\end{array}$ & $\begin{array}{c}806 \\
1127 \\
1236 \\
1288\end{array}$ & $\begin{array}{l}25 \\
29 \\
34 \\
22\end{array}$ \\
\hline Ulkansky (1996) & $\begin{array}{l}1 \\
2 \\
3 \\
4\end{array}$ & $\begin{array}{l}107.99 \\
108.49 \\
108.25 \\
108.39\end{array}$ & $\begin{array}{l}55.81 \\
55.74 \\
55.52 \\
55.07\end{array}$ & $\begin{array}{l}22369 \\
34641 \\
40033 \\
34859\end{array}$ & $\begin{array}{c}933 \\
1027 \\
827 \\
898\end{array}$ & $\begin{array}{l}24 \\
34 \\
48 \\
39\end{array}$ \\
\hline $\begin{array}{l}\text { Ust-Ilimsky (1991, } \\
\text { updated 1997) }\end{array}$ & 1 & 102.90 & 59.00 & 362019 & 14727 & 25 \\
\hline
\end{tabular}

Table 1: Test territories and test areas. 


\begin{tabular}{|c|c|c|c|c|c|c|c|c|c|c|c|}
\hline Track & $\begin{array}{c}\text { Orbit } \\
\text { ERS-1 }\end{array}$ & $\begin{array}{c}\text { Orbit } \\
\text { ERS-2 }\end{array}$ & $\begin{array}{c}\text { Date } \\
\text { ERS-1 }\end{array}$ & $\begin{array}{c}\text { Date } \\
\text { ERS-2 }\end{array}$ & $\begin{array}{l}\text { WMO } \\
\text { No. }\end{array}$ & $\begin{array}{c}\text { Latitude } \\
\text { (deg) }\end{array}$ & $\begin{array}{c}\text { Longitude } \\
\text { (deg) }\end{array}$ & $\begin{array}{l}\text { Temp } \\
\text { ERS-1 }\end{array}$ & $\begin{array}{c}\text { Temp } \\
\text { ERS-2 }\end{array}$ & $\begin{array}{c}\text { Rain } \\
\text { ERS-1 }\end{array}$ & $\begin{array}{c}\text { Rain } \\
\text { ERS-2 }\end{array}$ \\
\hline 305 & 32357 & 12684 & 19970922 & 19970923 & $\begin{array}{l}29570 \\
29675 \\
\end{array}$ & $\begin{array}{l}56.0 \\
55.1 \\
\end{array}$ & $\begin{array}{l}92.8 \\
93.4 \\
\end{array}$ & $\begin{array}{l}15.4 \\
11.6 \\
\end{array}$ & $\begin{array}{l}18.2 \\
12.8 \\
\end{array}$ & $\begin{array}{c}0.0 \\
\text { noV }\end{array}$ & $\begin{array}{l}0.0 \\
0.0 \\
\end{array}$ \\
\hline 319 & 32371 & 12698 & 19970923 & 19970924 & $\begin{array}{l}30117 \\
30405 \\
30504 \\
30603 \\
\end{array}$ & $\begin{array}{l}58.2 \\
55.4 \\
54.6 \\
53.9 \\
\end{array}$ & $\begin{array}{l}102.8 \\
101.0 \\
100.6 \\
102.1 \\
\end{array}$ & $\begin{array}{l}10.4 \\
13.9 \\
14.1 \\
13.5 \\
\end{array}$ & $\begin{array}{l}16.7 \\
15.4 \\
16.3 \\
16.1 \\
\end{array}$ & $\begin{array}{l}0.4 \\
0.0 \\
0.0 \\
0.0 \\
\end{array}$ & $\begin{array}{c}0.0 \\
\text { noV } \\
0.0 \\
0.0 \\
\end{array}$ \\
\hline 348 & 32400 & 12727 & 19970925 & 19970926 & $\begin{array}{l}29274 \\
29570 \\
29862 \\
\end{array}$ & $\begin{array}{l}58.1 \\
56.0 \\
53.8 \\
\end{array}$ & $\begin{array}{l}93.0 \\
92.8 \\
91.3 \\
\end{array}$ & $\begin{array}{l}\text { noV } \\
\text { noV } \\
\text { noV }\end{array}$ & $\begin{array}{c}7.2 \\
13.1 \\
17.7 \\
\end{array}$ & $\begin{array}{l}0.0 \\
0.0 \\
0.0 \\
\end{array}$ & $\begin{array}{l}0.0 \\
0.0 \\
0.0 \\
\end{array}$ \\
\hline 362 & 32414 & 12741 & 19970926 & 19970927 & $\begin{array}{l}24908 \\
29698 \\
30504\end{array}$ & $\begin{array}{l}60.3 \\
54.9 \\
54.6 \\
\end{array}$ & $\begin{array}{c}102.3 \\
99.0 \\
100.6\end{array}$ & $\begin{array}{c}8.5 \\
15.9 \\
15.5 \\
\end{array}$ & $\begin{array}{c}7.3 \\
13.3 \\
14.6 \\
\end{array}$ & $\begin{array}{c}0.0 \\
\text { noV } \\
0.0 \\
\end{array}$ & $\begin{array}{c}0.0 \\
2.0 \\
\text { noV } \\
\end{array}$ \\
\hline 391 & 32443 & 12770 & 19970928 & 19970929 & $\begin{array}{l}29263 \\
29274 \\
29363 \\
29562 \\
29756 \\
29759 \\
29862 \\
\end{array}$ & $\begin{array}{l}58.5 \\
58.1 \\
57.6 \\
56.1 \\
54.5 \\
54.3 \\
53.8 \\
\end{array}$ & $\begin{array}{l}92.2 \\
93.0 \\
92.3 \\
91.7 \\
89.9 \\
89.3 \\
91.3 \\
\end{array}$ & $\begin{array}{c}4.2 \\
4.8 \\
4.5 \\
5.4 \\
10.1 \\
8.9 \\
12.1 \\
\end{array}$ & $\begin{array}{c}3.6 \\
4.0 \\
3.0 \\
\text { noV } \\
3.8 \\
2.9 \\
6.9 \\
\end{array}$ & $\begin{array}{c}0.0 \\
0.1 \\
0.0 \\
0.0 \\
\text { noV } \\
0.0 \\
0.0 \\
\end{array}$ & $\begin{array}{l}0.0 \\
0.0 \\
0.0 \\
0.0 \\
0.0 \\
0.0 \\
0.0\end{array}$ \\
\hline 405 & 32457 & 12784 & 19970929 & 19970930 & $\begin{array}{l}24908 \\
29594 \\
29698 \\
29789 \\
29894 \\
\end{array}$ & $\begin{array}{l}60.3 \\
56.0 \\
54.9 \\
54.2 \\
53.6 \\
\end{array}$ & $\begin{array}{c}102.3 \\
98.0 \\
99.0 \\
97.0 \\
98.2 \\
\end{array}$ & $\begin{array}{l}2.4 \\
2.1 \\
3.2 \\
0.9 \\
0.6 \\
\end{array}$ & $\begin{array}{c}1.6 \\
2.2 \\
\text { noV } \\
1.5 \\
0.8 \\
\end{array}$ & $\begin{array}{l}2.0 \\
1.0 \\
0.1 \\
2.0 \\
4.1 \\
\end{array}$ & $\begin{array}{l}0.4 \\
0.5 \\
2.1 \\
0.1 \\
0.2 \\
\end{array}$ \\
\hline 434 & 32486 & 12813 & 19971001 & 19971002 & 29068 & 59.5 & 91.0 & 2.7 & 3.3 & 0.0 & 0.1 \\
\hline 448 & 32500 & 12827 & 19971002 & 19971003 & 29789 & 54.2 & 97.0 & 4.1 & 8.9 & 0.0 & noV \\
\hline 19 & 32572 & 12899 & 19971007 & 19971008 & 23884 & $\begin{array}{l}61.6 \\
61.0 \\
\end{array}$ & $\begin{array}{l}90.0 \\
89.6 \\
\end{array}$ & $\begin{array}{l}9.8 \\
9.2 \\
\end{array}$ & $\begin{array}{l}3.5 \\
5.5 \\
\end{array}$ & $\begin{array}{l}0.4 \\
0.0\end{array}$ & $\begin{array}{l}0.0 \\
0.0\end{array}$ \\
\hline 47 & 32600 & 12927 & 19971009 & 19971010 & $\begin{array}{l}30117 \\
30405 \\
30504 \\
30603 \\
\end{array}$ & $\begin{array}{l}58.2 \\
55.4 \\
54.6 \\
53.9 \\
\end{array}$ & $\begin{array}{l}102.8 \\
101.0 \\
100.6 \\
102.1 \\
\end{array}$ & $\begin{array}{l}\text { noV } \\
\text { noV } \\
\text { noV } \\
\text { noV }\end{array}$ & $\begin{array}{l}8.2 \\
9.0 \\
9.1 \\
7.9 \\
\end{array}$ & $\begin{array}{l}0.0 \\
0.0 \\
0.0 \\
0.0 \\
\end{array}$ & $\begin{array}{l}0.4 \\
0.0 \\
0.0 \\
0.0 \\
\end{array}$ \\
\hline 61 & 32614 & 12941 & 19971010 & 19971011 & $\begin{array}{l}30433 \\
30439 \\
30635 \\
30741 \\
30823 \\
\end{array}$ & $\begin{array}{l}55.8 \\
55.1 \\
53.4 \\
52.8 \\
51.8 \\
\end{array}$ & $\begin{array}{l}109.6 \\
109.8 \\
109.0 \\
110.0 \\
107.6 \\
\end{array}$ & $\begin{array}{l}3.3 \\
6.7 \\
5.4 \\
3.6 \\
7.1 \\
\end{array}$ & $\begin{array}{l}5.2 \\
6.8 \\
8.1 \\
9.5 \\
5.8 \\
\end{array}$ & $\begin{array}{l}0.0 \\
0.0 \\
0.0 \\
0.0 \\
0.0 \\
\end{array}$ & $\begin{array}{c}\text { noV } \\
0.0 \\
0.0 \\
0.0 \\
0.0 \\
\end{array}$ \\
\hline 104 & 32657 & 12984 & 19971013 & 19971014 & $\begin{array}{l}30337 \\
30537 \\
30635 \\
30823 \\
\end{array}$ & $\begin{array}{l}56.3 \\
54.0 \\
53.4 \\
51.8 \\
\end{array}$ & $\begin{array}{l}107.6 \\
108.3 \\
109.0 \\
107.6 \\
\end{array}$ & $\begin{array}{c}\text { noV } \\
7.3 \\
6.5 \\
4.2 \\
\end{array}$ & $\begin{array}{l}1.8 \\
3.7 \\
3.3 \\
2.8 \\
\end{array}$ & $\begin{array}{l}9.0 \\
0.0 \\
0.0 \\
0.0 \\
\end{array}$ & $\begin{array}{c}5.1 \\
0.4 \\
13.0 \\
0.1 \\
\end{array}$ \\
\hline 147 & 32700 & 13027 & 19971016 & 19971017 & $\begin{array}{l}30337 \\
30622 \\
30627 \\
30824\end{array}$ & $\begin{array}{l}56.3 \\
54.0 \\
53.1 \\
51.6 \\
\end{array}$ & $\begin{array}{l}107.6 \\
105.9 \\
105.5 \\
105.1\end{array}$ & $\begin{array}{l}2.0 \\
2.3 \\
2.3 \\
8.3 \\
\end{array}$ & $\begin{array}{c}1.5 \\
5.1 \\
5.3 \\
10.5\end{array}$ & $\begin{array}{c}3.0 \\
\text { noV } \\
3.0 \\
3.3 \\
\end{array}$ & $\begin{array}{l}3.3 \\
0.6 \\
0.5 \\
0.6 \\
\end{array}$ \\
\hline
\end{tabular}

Table 2: Environmental conditions during ERS-1/2 tandem acquisitions. The first five rows show track and orbit/date for ERS-1 and ERS-2 respectively. The next columns list the WMO stations and their coordinates. Temperature values for the overflight times are given in degree Celsius (average of temperature at UTC 3:00 and 6:00). The last two columns show estimated rainfall in millimeters within 24 hours before acquisitions (sum of 12 hourly rainfall reported for UTC 0:00 and UTC 12:00). "noV" indicates missing values. 


\begin{tabular}{cc}
\hline Class & $|\gamma| \pm \operatorname{StDev}(\gamma)$ \\
\hline Bare soil & $0.85 \pm 0.04$ \\
Sparse shrub & $0.79 \pm 0.05$ \\
$1-20 \mathrm{~m}^{3} / \mathrm{ha}$ & $0.68 \pm 0.13$ \\
$21-50 \mathrm{~m}^{3} / \mathrm{ha}$ & $0.53 \pm 0.13$ \\
$51-80 \mathrm{~m}^{3} / \mathrm{ha}$ & $0.45 \pm 0.13$ \\
$81-130 \mathrm{~m}^{3} / \mathrm{ha}$ & $0.40 \pm 0.13$ \\
$131-200 \mathrm{~m}^{3} / \mathrm{ha}$ & $0.33 \pm 0.13$ \\
$>200 \mathrm{~m}^{3} / \mathrm{ha}$ & $0.29 \pm 0.12$ \\
\hline
\end{tabular}

Table 3: Generalised coherence signatures used by Gaveau et al. (in press).

\begin{tabular}{|c|c|c|c|c|c|c|c|c|c|}
\hline Enterprise & Track & Frame & Dates ERS & Date JERS & Area (ha) & $0-20$ & $20-50$ & $50-80$ & $>80$ \\
\hline Bolshe-Murtinsky & 348 & 2457 & $\begin{array}{c}\text { 25/26 Sep. } \\
1997\end{array}$ & $\begin{array}{l}2 \text { Aug. } \\
1998\end{array}$ & 34351 & 19.17 & 13.65 & 6.14 & 61.04 \\
\hline Nizhne-Udinsky & 362 & 2493 & $\begin{array}{c}\text { 26/27 Sep. } \\
1997\end{array}$ & $\begin{array}{c}\text { 6 June } \\
1998\end{array}$ & 25908 & 38.86 & 1.55 & 2.04 & 57.55 \\
\hline Chunsky & 491 & 2439 & $\begin{array}{c}\text { 5/6 Oct. } \\
1997\end{array}$ & $\begin{array}{c}16 \text { June } \\
1998\end{array}$ & 41020 & 35.59 & 5.35 & 1.11 & 57.95 \\
\hline Primorsky & 47 & 2475 & $\begin{array}{l}\text { 9/10 Oct. } \\
1997\end{array}$ & $\begin{array}{c}\text { 2 June } \\
1998\end{array}$ & 34271 & 10.98 & 11.22 & 10.75 & 67.05 \\
\hline Ulkansky & 104 & 2493 & $\begin{array}{c}\text { 13/14 Oct. } \\
1997\end{array}$ & $\begin{array}{c}23 \text { May } \\
1998\end{array}$ & 13534 & 0.37 & 5.44 & 12.58 & 81.61 \\
\hline
\end{tabular}

Table 4: Satellite data and testsites used for estimating model parameters. The first column shows the name of the forest enterprise. The second to forth columns give track, frame and acquisition dates of the ERS tandem pairs, the fifth column the JERS acquisition date. Then follows the total area of all testsites (after shrinking of polygons to account for co-registration errors) covered by the satellite data and finally, the area percentages for the four forest classes $0-20,20-50,50-80$, and $>80 \mathrm{~m}^{3} /$ ha. 


\begin{tabular}{|l|ll|ll||}
\hline Class & ERS Coherence $\gamma$ & & \multicolumn{2}{|l||}{ JERS Intensity $\sigma^{0}[\mathrm{~dB}]$} \\
& Mean & StDev & Mean & StDev \\
\hline $0-20 \mathrm{~m}^{3} / \mathrm{ha}$ & $0.304+1.535 \cdot \gamma_{H}$ & 0.08 & $\sigma_{H}-2.24$ & 1.0 \\
$20-50 \mathrm{~m}^{3} / \mathrm{ha}$ & $0.248+1.436 \cdot \gamma_{H}$ & 0.08 & $\sigma_{H}-1.78$ & 1.0 \\
$50-80 \mathrm{~m}^{3} / \mathrm{ha}$ & $0.194+1.341 \cdot \gamma_{H}$ & 0.08 & $\sigma_{H}-1.34$ & 1.0 \\
$>80 \mathrm{~m}^{3} / \mathrm{ha}$ & $0.064+1.113 \cdot \gamma_{H}$ & 0.08 & $\sigma_{H}-0.38$ & 1.0 \\
Water & 0.16 & 0.04 & -17 & 1.8 \\
Smooth surfaces & 0.82 & 0.08 & -15 & 1.3 \\
\hline
\end{tabular}

Table 5: Class statistics used as input to a maximum likelihood algorithm. The coherence values for the four forest classes are determined according to Eq. (5) and the JERS backscatter values according to Eq. (6). $\gamma_{H}$ and $\sigma_{H}$ are histogram parameters (Section 6.2).

\begin{tabular}{|c|c|c|c|c|c|c|c|c|}
\hline \multirow[b]{2}{*}{$\begin{array}{c}\text { remotely } \\
\text { sensed data }\end{array}$} & \multicolumn{8}{|c|}{ ground survey } \\
\hline & water & $\begin{array}{l}\text { smooth } \\
\text { surfaces }\end{array}$ & $\begin{array}{c}<=20 \\
{\left[\mathrm{~m}^{3} / \mathrm{ha}\right]}\end{array}$ & $\begin{array}{c}20-50 \\
{\left[\mathrm{~m}^{3} / \mathrm{ha}\right]}\end{array}$ & $\begin{array}{c}50-80 \\
{\left[\mathrm{~m}^{3} / \mathrm{ha}\right]}\end{array}$ & $\begin{array}{c}>80 \\
{\left[\mathrm{~m}^{3} / \mathrm{ha}\right]}\end{array}$ & total & $\begin{array}{c}\text { user } \\
\text { accuracy }\end{array}$ \\
\hline water & 95 & & & & & & 95 & $100 \%$ \\
\hline smooth & & 137 & 20 & 1 & & & 158 & $87 \%$ \\
\hline$<=20$ & & 19 & 908 & 36 & 5 & 9 & 977 & $93 \%$ \\
\hline $20-50$ & & 1 & 76 & 576 & 39 & 15 & 707 & $81 \%$ \\
\hline $50-80$ & & & 12 & 33 & 881 & 58 & 984 & $90 \%$ \\
\hline$>80$ & & & & 9 & 120 & 2182 & 2311 & $94 \%$ \\
\hline total & 95 & 157 & 1016 & 655 & 1045 & 2264 & 5232 & \\
\hline $\begin{array}{l}\text { producer } \\
\text { accuracy }\end{array}$ & $100 \%$ & $87 \%$ & $89 \%$ & $88 \%$ & $84 \%$ & $96 \%$ & & \\
\hline
\end{tabular}

Table 6: Pooled confusion matrix for seven ground survey (GS) sites. Numbers are 1 ha (4 pixels) sample plots determined by Russian forestry experts. From Balzter et al. (in press). 


\section{Figures}

Fig. 1: Location of test territories and test areas. Also shown are the five ERS frames used for model development (Table 4).

Fig. 2: Mosaic of 122 coherence images derived from ERS-1/2 tandem acquisitions in fall 1997 and, for a few images, summer 1998. Indicated are three satellite tracks (104, 147, and 405) where Table 2 shows that significant rainfall was recorded at stations along the track. Generally, areas of low coherence are most likely associated with rainfall.

Fig. 3: Characteristics of the SIBERIA mosaic. a) Relative coverage of fall 1997 (grey) and summer 1998 (black) ERS tandem data; b) Relative coverage of GEC frames (grey: 74 of 122) and GTC frames (black: 48 of 122) in the mosaic.

Fig. 4: Mosaic of JERS backscatter images after remapping the original JERS tracks onto the ERS reference frame system.

Fig. 5: Scatterplots of the ERS coherence $\gamma$ versus growing stock volume $v$ in $\mathrm{m}^{3} /$ ha for six selected test areas located in the territories Primorsky, Nizhne-Udinsky, Chunsky, BolsheMurtinsky, Juzhno-Baikalsky and Shestakovsky. The figures show the track and frame numbers of the ERS tandem data, the acquisition dates, and the baselines.

Fig. 6: Scatterplot of dense-forest coherence versus non-forest coherence from 42 training data sets. The dotted lines indicate the uncertainty range of the parameters $(+/-$ one standard deviation).

Fig. 7: Scatterplot of JERS backscattering coefficient $\sigma^{0}$ versus growing stock volume for a testsite located in the Irbeisky forest enterprise centered around $55.25^{\circ} \mathrm{N}, 96.08^{\circ} \mathrm{E}$. The JERS image was acquired on June 16, 1998. Modified after Balzter et al. (in press).

Fig. 8: Two-dimensional histogram of ERS coherence $\gamma$ and JERS backscattering coefficient $\sigma^{0}$ for a region around Bratsk (ERS track 47, frame 2475). The coherence image was derived 
from the ERS tandem pair data from October 9/10, 1997. The JERS data were acquired on June 2 and 4, 1998. Grey-scale is cyclic to better illustrate the relative density of samples in each cluster.

Fig. 9: Image histograms of $\gamma$ and $\sigma^{0}$ (thick solid lines) of the five satellite frames given in Table 4. Also shown are the histograms of the four forest classes (normalized to $60 \%$ ) derived using the forest inventory data base. The four class histograms were smoothed to improve the appearance. The numbers 1 to 4 indicate the classes in order of increasing stem volume, i.e. $0-20,20-50,50-80$, and $>80 \mathrm{~m}^{3} / \mathrm{ha}$.

Fig. 10: Median values of ERS coherence $\gamma$ for the four forest classes 0-20, 20-50, 50-80, and $>80 \mathrm{~m}^{3} /$ ha for the five test territories given in Table 4 (large symbols). The model results according to Eq. (5) for the respective image frames are indicated by the small symbols.

Fig. 11: Modeled coherence versus histogram parameter $\gamma_{H}$ of the four forest classes 0-20, 2050, 50-80, and $>80 \mathrm{~m}^{3} / \mathrm{ha}$ according to Eqs. (4) and (5). Also shown are histogram peaks extracted from the 122 satellite frames.

Fig. 12: Median values of JERS backscatter coefficient $\sigma^{0}$ for the four forest classes $0-20,20$ 50, 50-80, and $>80 \mathrm{~m}^{3} /$ ha for the five test territories given in Table 4 (large symbols). The model results according to Eq. (6) for the respective image frames are indicated by the small symbols.

Fig. 13: Modeled JERS $\sigma^{0}$ versus histogram parameter $\sigma_{H}$ of the four forest classes $0-20,20$ 50, 50-80, and $>80 \mathrm{~m}^{3} /$ ha according to Eqs. (6) and (7). Also shown are histogram peaks extracted from the 122 satellite frames.

Fig. 14: Mosaic of classified radar images. The UTM (Zone 47) grid is overlaid (meters) to give scale. (C) European Commission ENV4-CT97-0743-SIBERIA, ESA 97/98, NASA GBFM, DLR. 


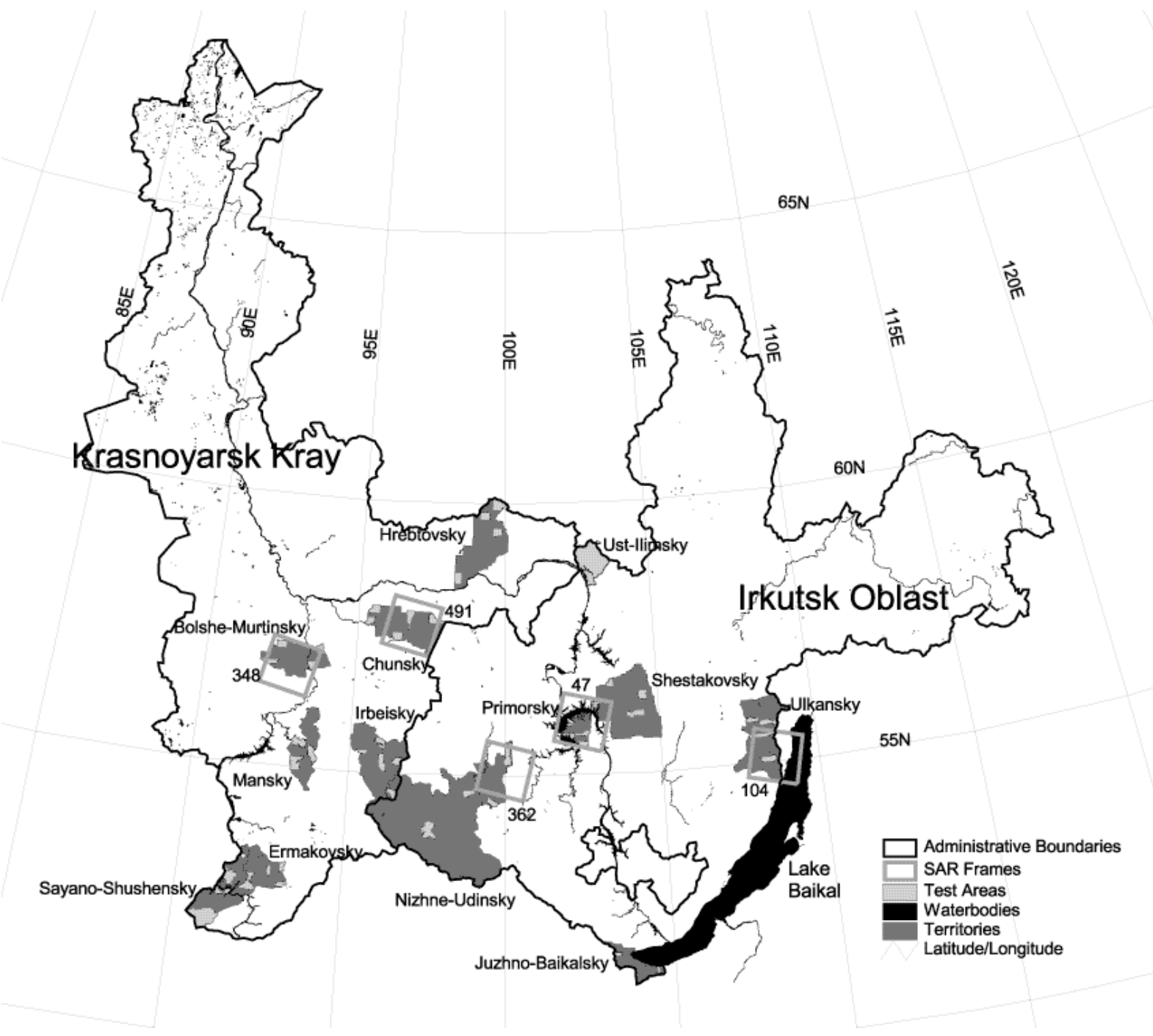

Fig. 1: Location of test territories and test areas. Also shown are the five ERS frames used for model development (Table 4). 


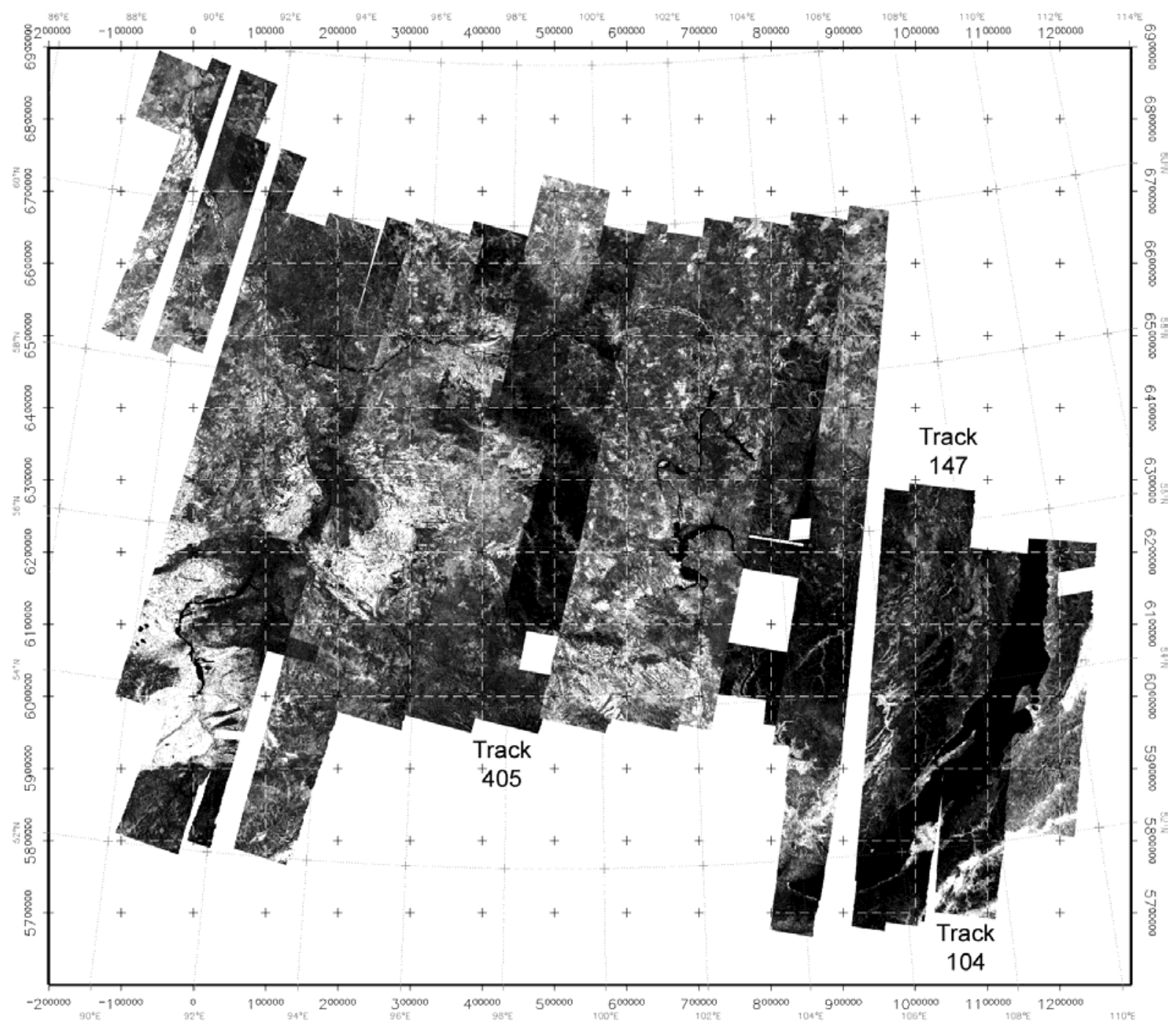

Fig. 2: Mosaic of 122 coherence images derived from ERS-1/2 tandem acquisitions in fall 1997 and, for a few images, summer 1998. Indicated are three satellite tracks $(104,147$, and 405) where Table 2 shows that significant rainfall was recorded at stations along the track. Generally, areas of low coherence are most likely associated with rainfall. 
a)

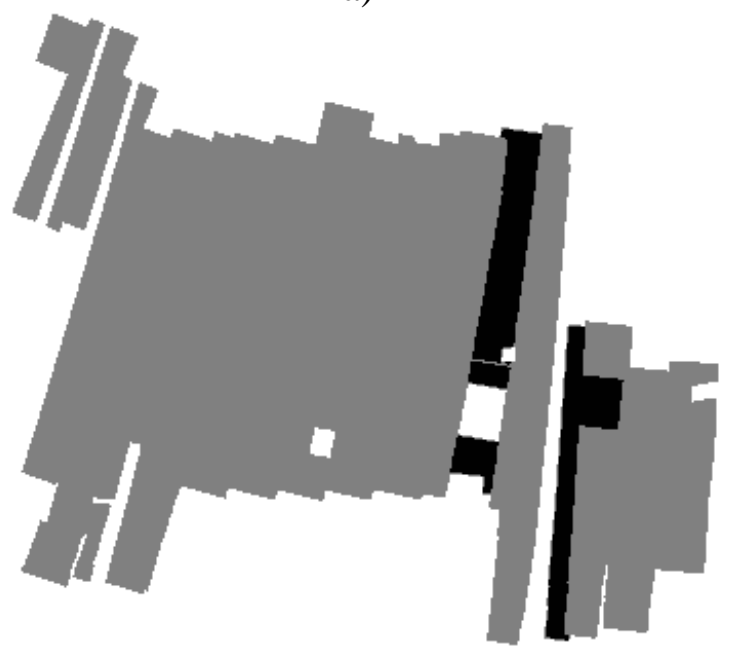

b)

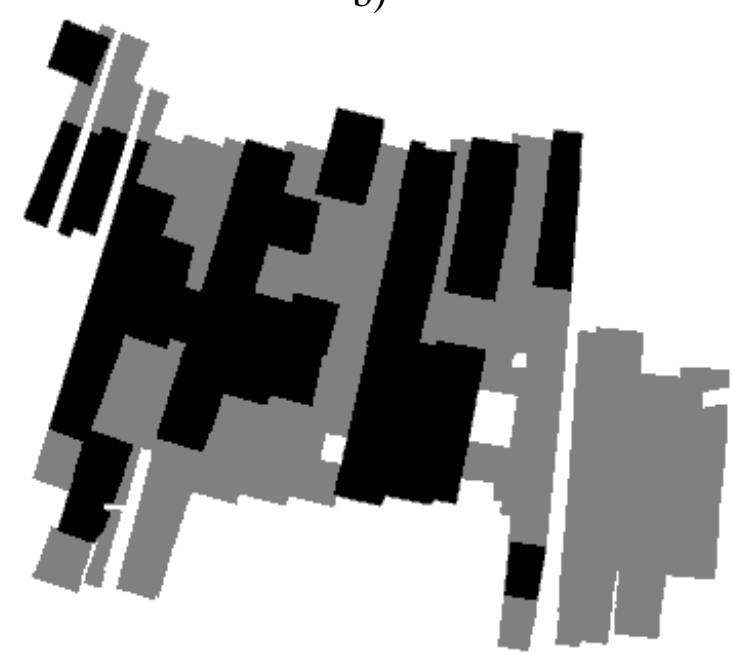

Fig. 3: Characteristics of the SIBERIA mosaic. a) Relative coverage of fall 1997 (grey) and summer 1998 (black) ERS tandem data; b) Relative coverage of GEC frames (grey: 74 of 122) and GTC frames (black: 48 of 122) in the mosaic. 


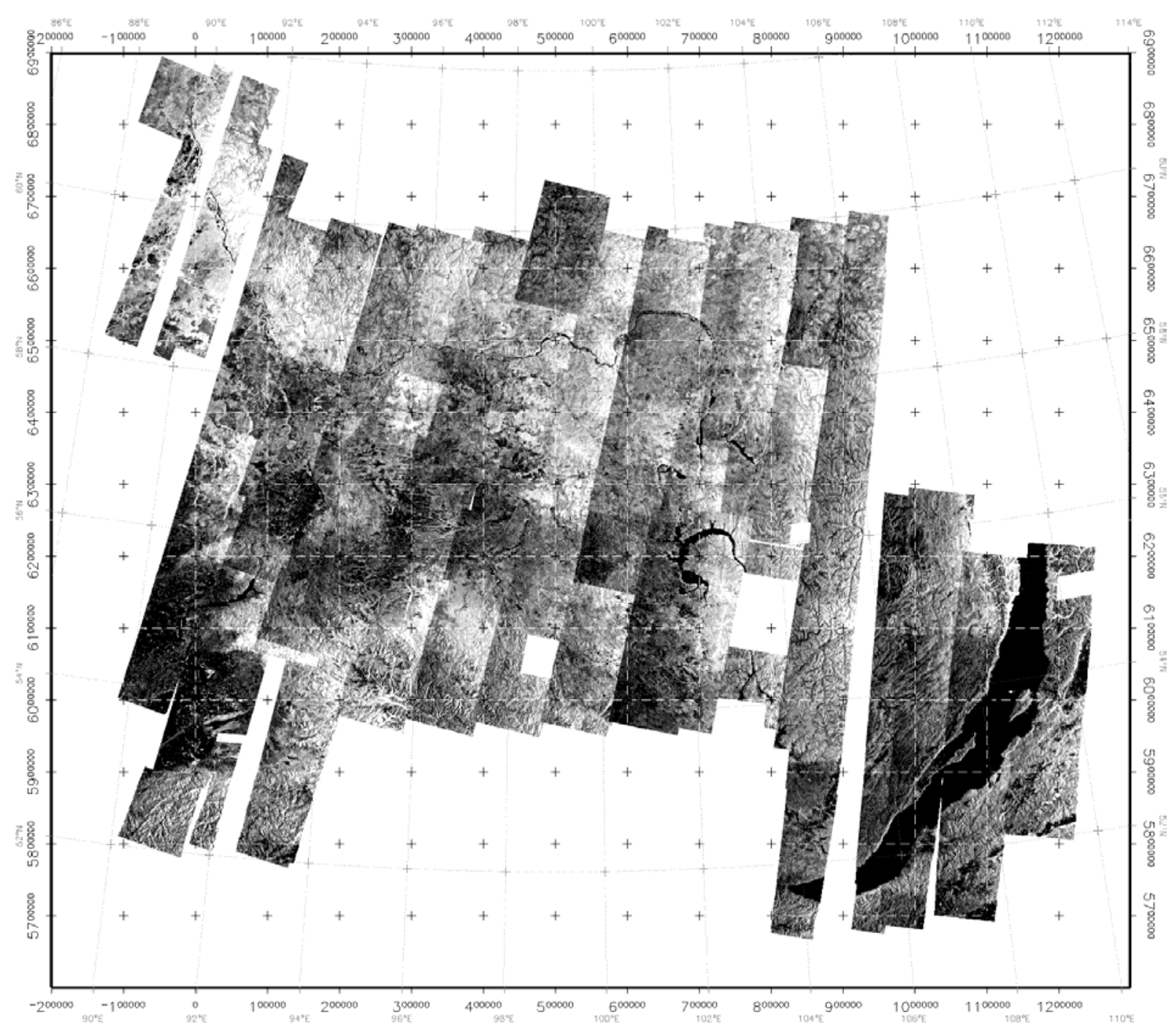

Fig. 4: Mosaic of JERS backscatter images after remapping the original JERS tracks onto the ERS reference frame system. 

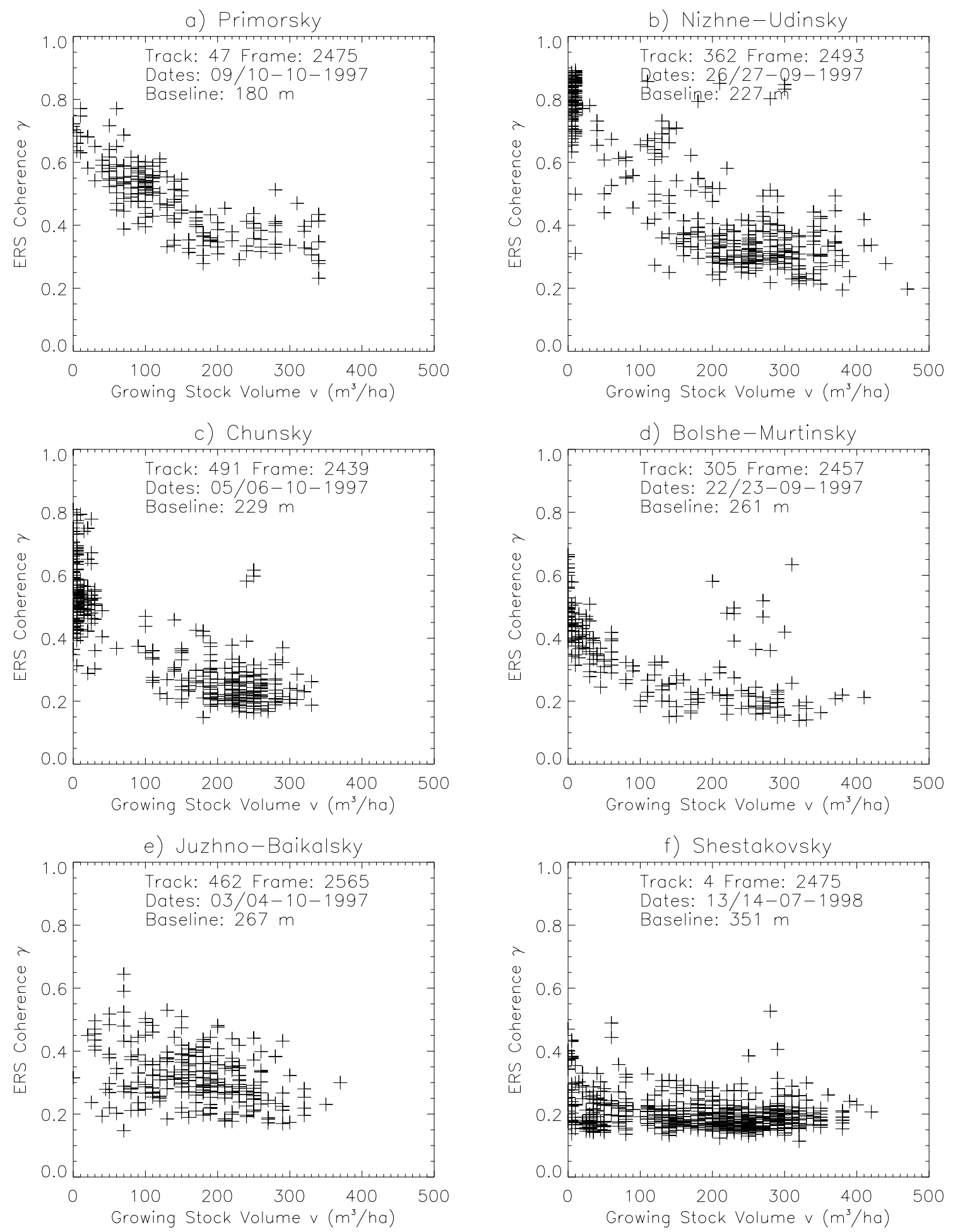

Fig. 5: Scatterplots of the ERS coherence $\gamma$ versus growing stock volume $v$ in $\mathrm{m}^{3} /$ ha for six selected test areas located in the territories Primorsky, Nizhne-Udinsky, Chunsky, BolsheMurtinsky, Juzhno-Baikalsky and Shestakovsky. The figures show the track and frame numbers of the ERS tandem data, the acquisition dates, and the baselines. 


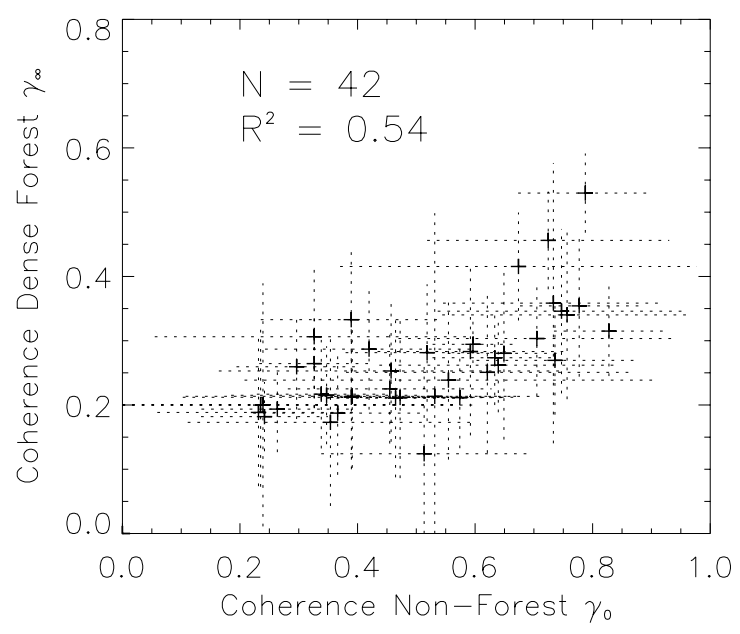

Fig. 6: Scatterplot of dense-forest coherence versus non-forest coherence from 42 training data sets. The dotted lines indicate the uncertainty range of the parameters (+/- one standard deviation).

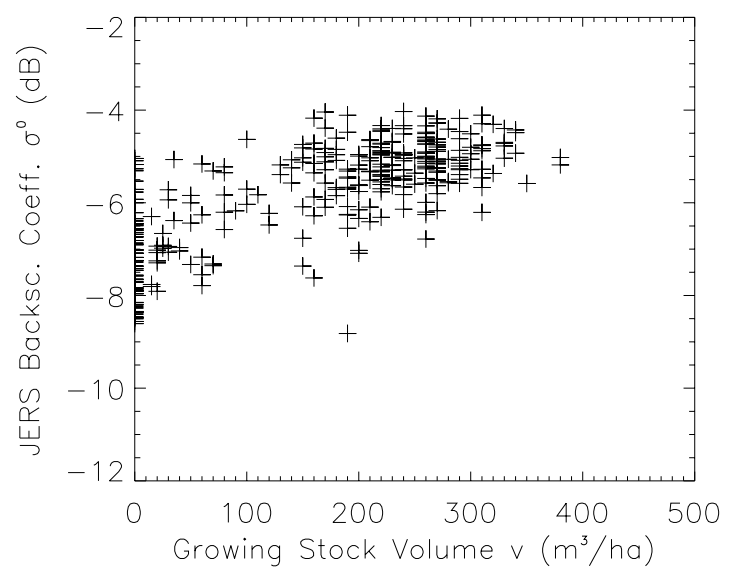

Fig. 7: Scatterplot of JERS backscattering coefficient $\sigma^{0}$ versus growing stock volume for a testsite located in the Irbeisky forest enterprise centered around $55.25^{\circ} \mathrm{N}, 96.08^{\circ} \mathrm{E}$. The JERS image was acquired on June 16, 1998. Modified after Balzter et al. (in press). 


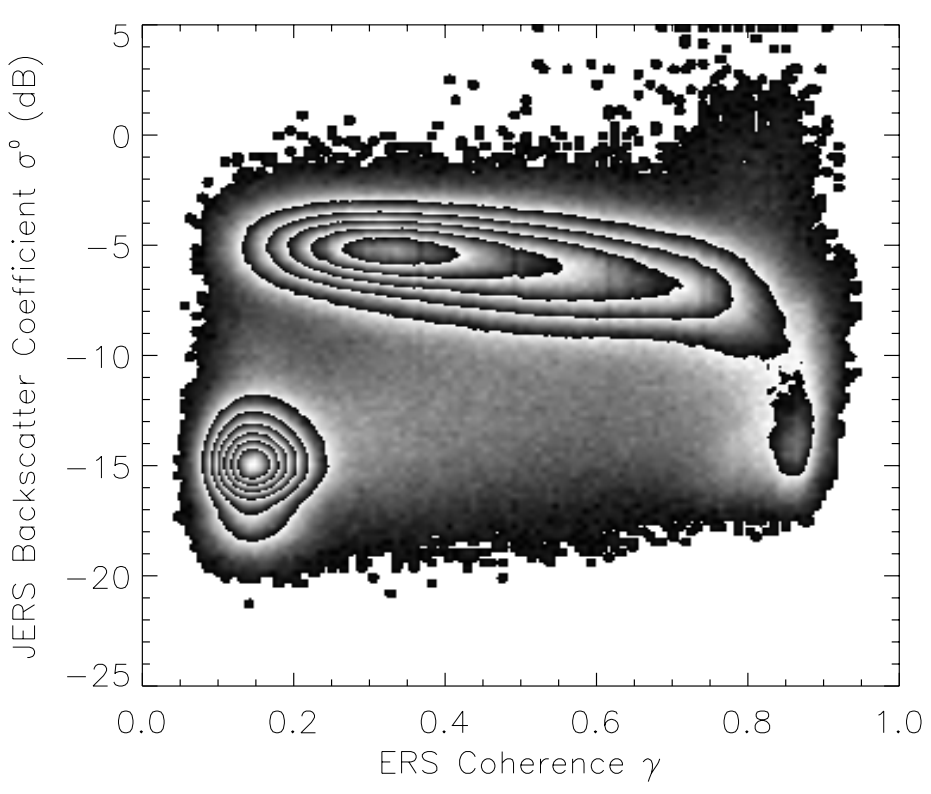

Fig. 8: Two-dimensional histogram of ERS coherence $\gamma$ and JERS backscattering coefficient $\sigma^{0}$ for a region around Bratsk (ERS track 47, frame 2475). The coherence image was derived from the ERS tandem pair data from October 9/10, 1997. The JERS data were acquired on June 2 and 4, 1998. Grey-scale is cyclic to better illustrate the relative density of samples in each cluster. 

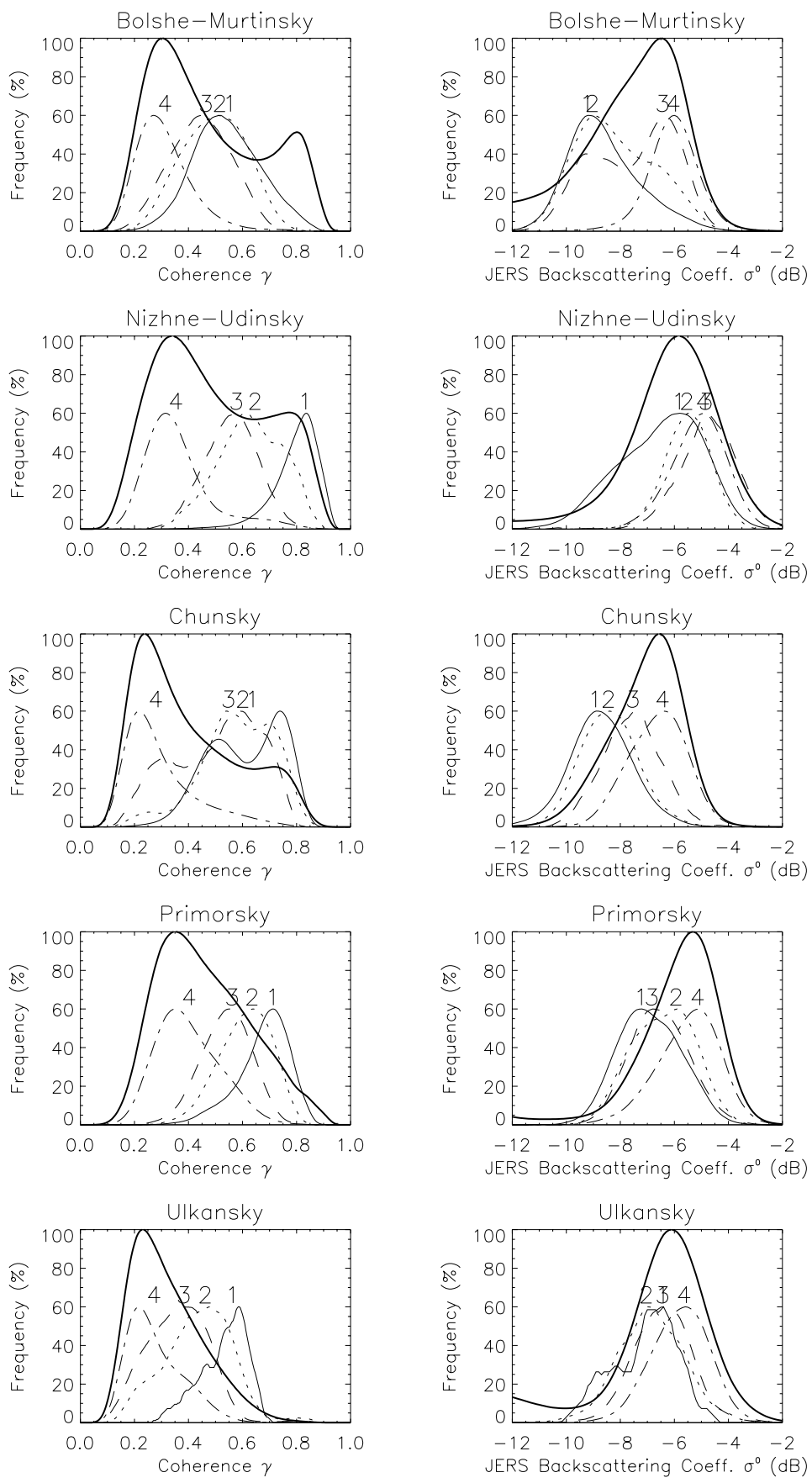

Fig. 9: Image histograms of $\gamma$ and $\sigma^{0}$ (thick solid lines) of the five satellite frames given in Table 4. Also shown are the histograms of the four forest classes (normalized to $60 \%$ ) derived using the forest inventory data base. The four class histograms were smoothed to improve the appearance. The numbers 1 to 4 indicate the classes in order of increasing stem volume, i.e. $0-20,20-50,50-80$, and $>80 \mathrm{~m}^{3} /$ ha. 


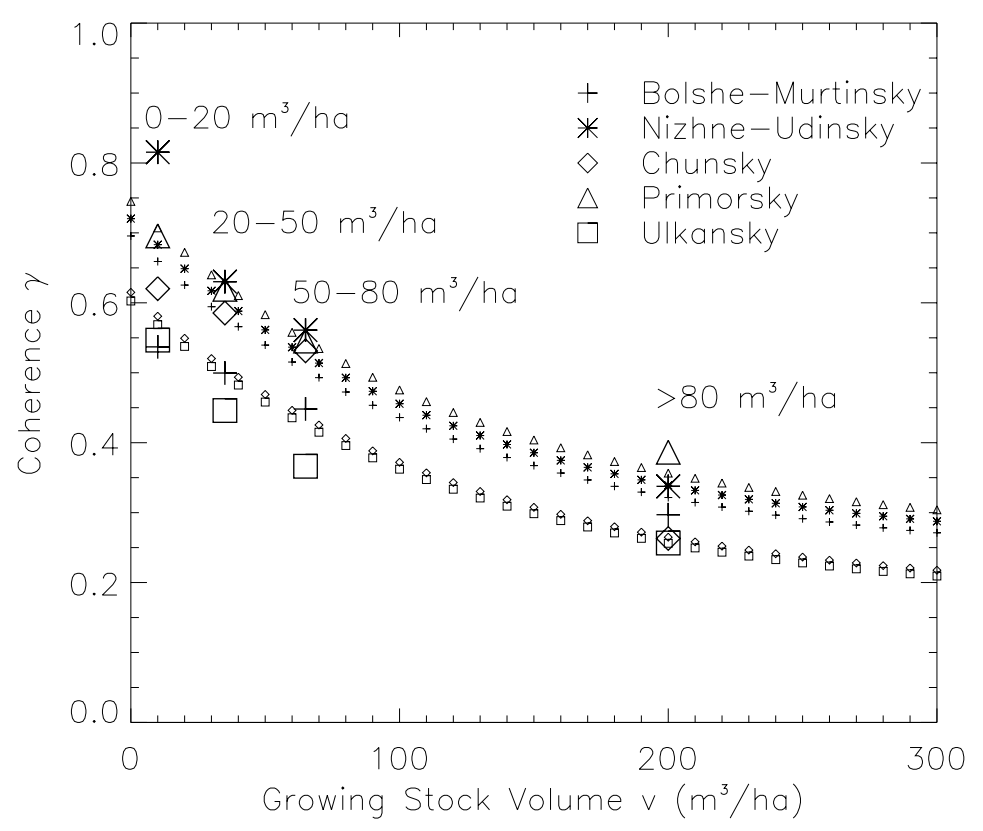

Fig. 10: Median values of ERS coherence $\gamma$ for the four forest classes 0-20, 20-50, 50-80, and $>80 \mathrm{~m}^{3} /$ ha for the five test territories given in Table 4 (large symbols). The model results according to Eq. (5) for the respective image frames are indicated by the small symbols.

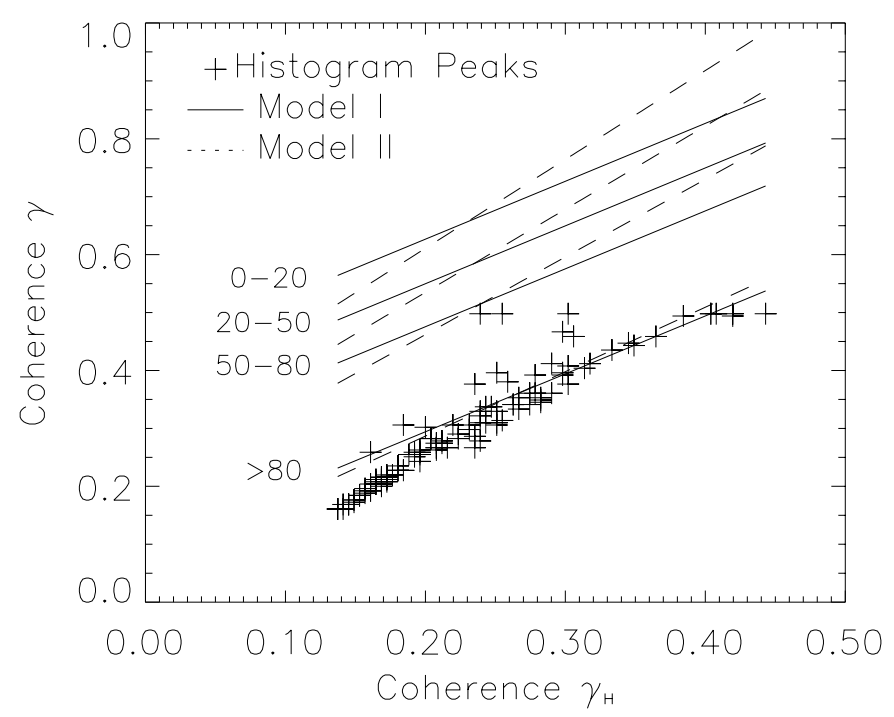

Fig. 11: Modeled coherence versus histogram parameter $\gamma_{H}$ of the four forest classes $0-20,20-$ 50, 50-80, and $>80 \mathrm{~m}^{3} /$ ha according to Eqs. (4) and (5). Also shown are histogram peaks extracted from the 122 satellite frames. 


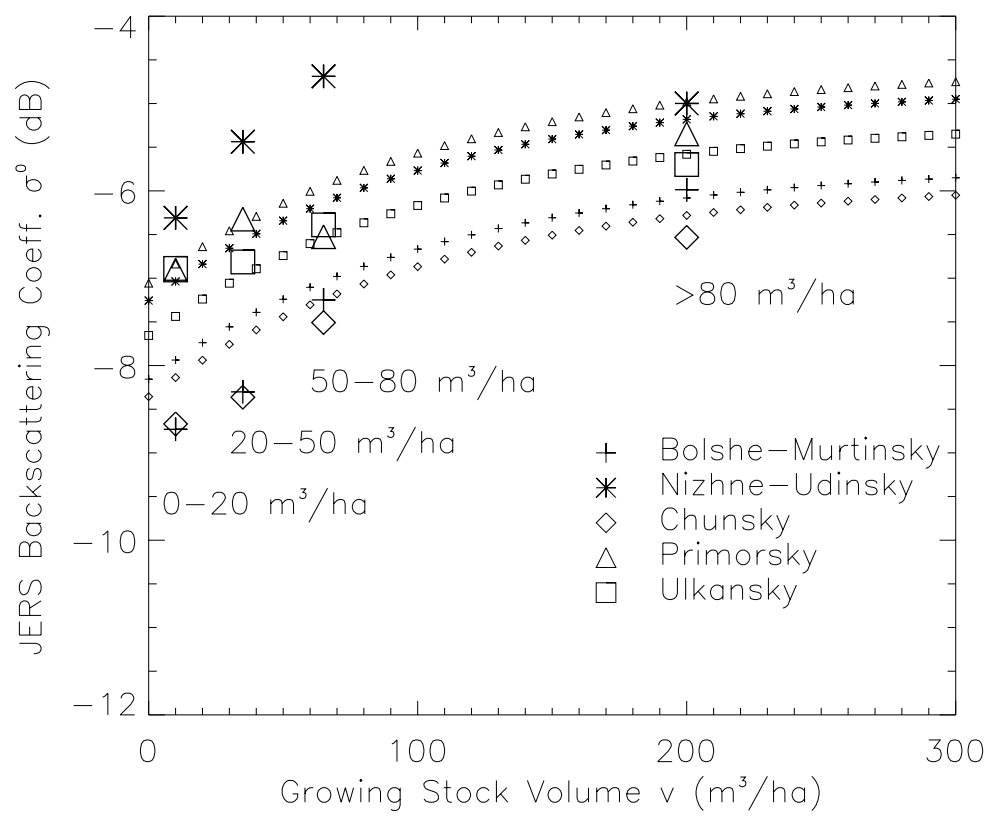

Fig. 12: Median values of JERS backscatter coefficient $\sigma^{0}$ for the four forest classes $0-20,20$ 50, 50-80, and $>80 \mathrm{~m}^{3} /$ ha for the five test territories given in Table 4 (large symbols). The model results according to Eq. (6) for the respective image frames are indicated by the small symbols.

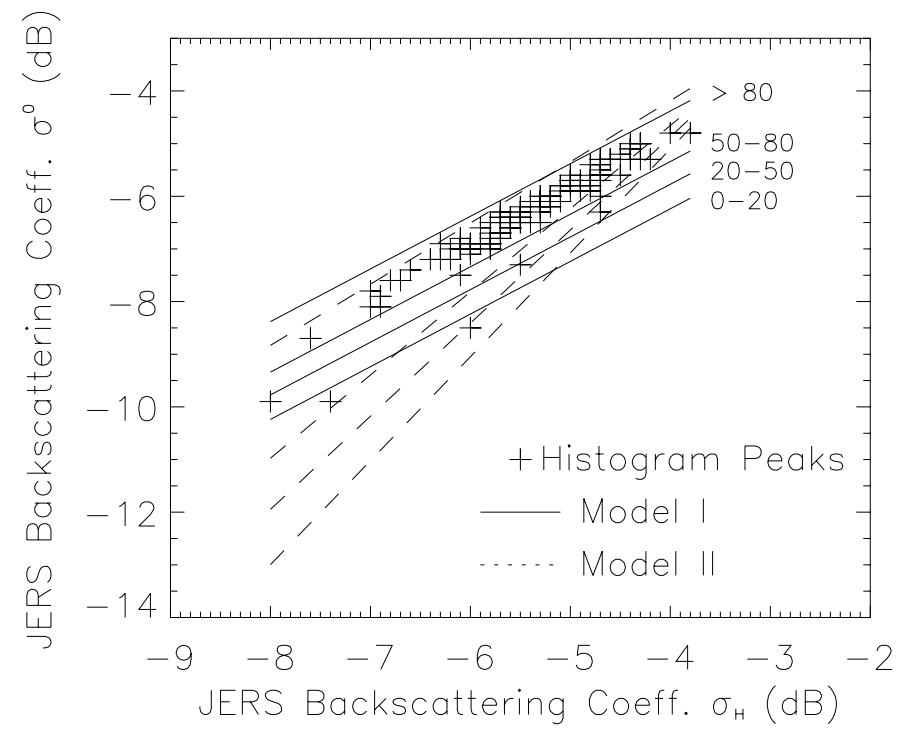

Fig. 13: Modeled JERS $\sigma^{0}$ versus histogram parameter $\sigma_{H}$ of the four forest classes $0-20,20$ 50, 50-80, and $>80 \mathrm{~m}^{3} /$ ha according to Eqs. (6) and (7). Also shown are histogram peaks extracted from the 122 satellite frames. 


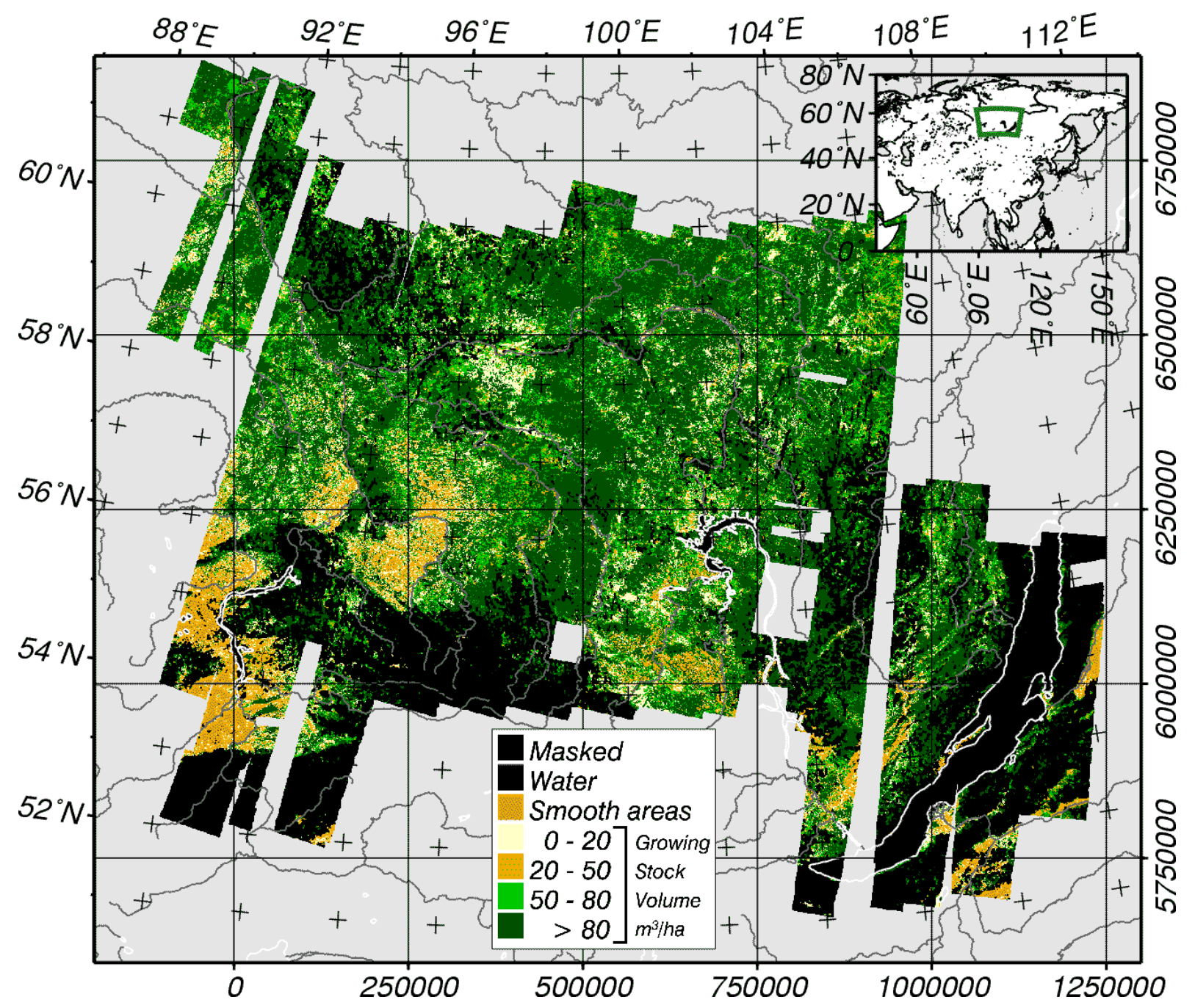

Fig. 14: Mosaic of classified radar images. The UTM (Zone 47) grid is overlaid (meters) to give scale. (C) European Commission ENV4-CT97-0743-SIBERIA, ESA 97/98, NASA GBFM, DLR. 